\title{
Information Technology for Active Ageing: A Review of Theory and Practice
}





\section{Information Technology for Active Ageing: A Review of Theory and Practice}

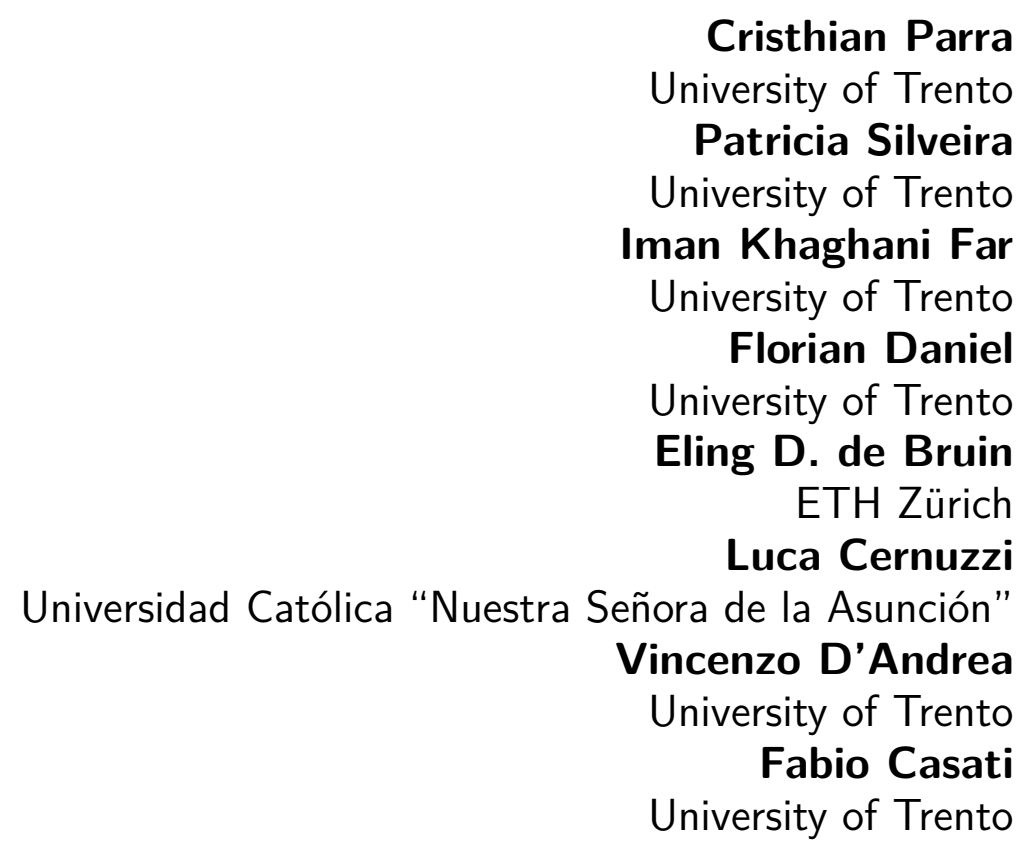

now

the essence of knowledge

Boston — Delft 


\section{Foundations and Trends ${ }^{\circledR}$ in Human-Computer Interaction}

Published, sold and distributed by: now Publishers Inc.

PO Box 1024

Hanover, MA 02339

United States

Tel. +1-781-985-4510

www.nowpublishers.com

sales@nowpublishers.com

Outside North America:

now Publishers Inc.

PO Box 179

2600 AD Delft

The Netherlands

Tel. +31-6-51115274

The preferred citation for this publication is

C. Parra. Information Technology for Active Ageing: A Review of Theory and Practice. Foundations and Trends ${ }^{\circledR}$ in Human-Computer Interaction, vol. 7, no. 4, pp. 351-447, 2013.

This Foundations and Trends ${ }^{\circledR}$ issue was typeset in ${ }^{A} T_{E} X$ using a class file designed by Neal Parikh. Printed on acid-free paper.

ISBN: 978-1-60198-922-2

(C) 2014 C. Parra

All rights reserved. No part of this publication may be reproduced, stored in a retrieval system, or transmitted in any form or by any means, mechanical, photocopying, recording or otherwise, without prior written permission of the publishers.

Photocopying. In the USA: This journal is registered at the Copyright Clearance Center, Inc., 222 Rosewood Drive, Danvers, MA 01923. Authorization to photocopy items for internal or personal use, or the internal or personal use of specific clients, is granted by now Publishers Inc for users registered with the Copyright Clearance Center (CCC). The 'services' for users can be found on the internet at: www.copyright.com

For those organizations that have been granted a photocopy license, a separate system of payment has been arranged. Authorization does not extend to other kinds of copying, such as that for general distribution, for advertising or promotional purposes, for creating new collective works, or for resale. In the rest of the world: Permission to photocopy must be obtained from the copyright owner. Please apply to now Publishers Inc., PO Box 1024, Hanover, MA 02339, USA; Tel. +1 781871 0245; www.nowpublishers.com; sales@nowpublishers.com

now Publishers Inc. has an exclusive license to publish this material worldwide. Permission to use this content must be obtained from the copyright license holder. Please apply to now Publishers, PO Box 179, 2600 AD Delft, The Netherlands, www.nowpublishers.com; e-mail: sales@nowpublishers.com 


\title{
Foundations and Trends ${ }^{\circledR}$ in Human-Computer Interaction
}

\author{
Volume 7, Issue 4, 2013
}

Editorial Board

\section{Editor-in-Chief}

Ben Bederson

University of Maryland

United States

\section{Editors}

Gregory Abowd

Georgia Institute of Technology

Batya Friedman

University of Washington

Jon Froehlich

University of Maryland

Jonathan Grudin

Microsoft Research

Jason Hong

Carnegie Mellon University

Juan Pablo Hourcade

University of Iowa

Karrie Karahalios

University of Illinois

at Urbana-Champaign

Gary Klein

The MITRE Corporation

\author{
Joe Konstan \\ University of Minnesota \\ Chris North \\ Virginia Tech \\ Yvonne Rogers \\ University College London \\ Orit Shaer \\ Wellesley College \\ Desney Tan \\ Microsoft Research \\ Kentaro Toyama \\ UC Berkeley \\ Jacob Wobbrock \\ University of Washington
}




\section{Editorial Scope}

\section{Topics}

Foundations and Trends ${ }^{\circledR}$ in Human-Computer Interaction publishes surveys and tutorials on the foundations of human-computer interaction. The scope is broad. The list of topics below is meant to illustrate some of the coverage, and is not intended to be an exhaustive list.

- History of the research community

- Design and evaluation

- Theory

- Technology
- Computer supported cooperative work

- Interdisciplinary influence

- Advanced topics and trends

\section{Information for Librarians}

Foundations and Trends ${ }^{\circledR}$ in Human-Computer Interaction, 2013, Volume 7, 4 issues. ISSN paper version 1551-3955. ISSN online version 1551-3963. Also available as a combined paper and online subscription. 
Foundations and Trends ${ }^{\circledR}$ in Human-Computer Interaction

Vol. 7, No. 4 (2013) 351-447

(C) 2014 C. Parra

DOI: $10.1561 / 1100000053$

\title{
Information Technology for Active Ageing: A Review of Theory and Practice
}

\author{
Cristhian Parra \\ University of Trento \\ Patricia Silveira \\ University of Trento \\ Iman Khaghani Far \\ University of Trento \\ Florian Daniel \\ University of Trento \\ Eling D. de Bruin \\ ETH Zürich \\ Luca Cernuzzi \\ Universidad Católica "Nuestra Señora de la Asunción" \\ Vincenzo D'Andrea \\ University of Trento \\ Fabio Casati \\ University of Trento
}





\section{Contents}

\begin{tabular}{lll}
\hline 1 & Introduction & 3
\end{tabular}

\begin{tabular}{lll}
\hline 2 & What is Ageing? & 7
\end{tabular}

2.1 What is Active Ageing? . . . . . . . . . . . . . . . 9

2.2 Determinants of Active Ageing . . . . . . . . . . . . . . 11

\begin{tabular}{lll}
\hline 3 & IT for Active Ageing & 13
\end{tabular}

3.1 Objectives of IT for Active Ageing . . . . . . . . . . . . 13

3.2 Challenges of IT Design for Active Ageing . . . . . . . . . 15

$\begin{array}{lll}4 & \text { Evaluation Framework } & 19\end{array}$

4.1 Literature Selection . . . . . . . . . . . . . . . . . . . . 24

$\begin{array}{lll}5 & \text { IT for Prevention } & \mathbf{2 5}\end{array}$

5.1 Applications for Prevention . . . . . . . . . . . . . . . . 25

5.2 Discussion . . . . . . . . . . . . . . . . . 31

$6 \quad$ IT for Compensation $\quad 35$

6.1 Applications for Compensation . . . . . . . . . . . . . . . 35

6.2 Discussion . . . . . . . . . . . . . . . . . . . . . . . . . . . 41

\begin{tabular}{|lll}
7 & IT for Care Support & 43
\end{tabular} 
7.1 Applications for Care . . . . . . . . . . . . . . . . . . . . . 43

7.2 Discussion $\ldots \ldots \ldots \ldots$. . . . . . . . . . . . . . . . . . . . 47

\begin{tabular}{lll}
\hline 8 & IT for Enhancement & 51
\end{tabular}

8.1 Applications for Enhancement . . . . . . . . . . . . . . . . . 51

8.2 Discussion . . . . . . . . . . . . . . . . . . . . . . . . . 58

9 Limitations of this review and related work 63

10 Summary and Outlook $\quad 69$

\begin{tabular}{ll}
\hline Appendices & 77
\end{tabular}

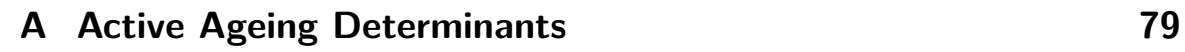

\begin{tabular}{ll}
\hline References & 85
\end{tabular} 


\begin{abstract}
Active Ageing aims to foster a physically, mentally and socially active lifestyle as a person ages. It is a complex, multi-faceted problem that involves a variety of different actors, such as policy makers, doctors, care givers, family members, friends and, of course, older adults. This review aims to understand the role of a new actor, which increasingly plays the role of enabler and facilitator, i.e., that of the technology provider. The review specifically focuses on Information Technology (IT), with a particular emphasis on software applications, and on how IT can prevent decline, compensate for lost capabilities, aid care, and enhance existing capabilities. The analysis confirms the crucial role of IT in Active Ageing, shows that Active Ageing requires a multidisciplinary approach, and identifies the need for better integration of hardware, software, the environment and the involved actors.
\end{abstract}

C. Parra. Information Technology for Active Ageing: A Review of Theory and Practice. Foundations and Trends ${ }^{\circledR}$ in Human-Computer Interaction, vol. 7, no. 4, pp. 351-447, 2013.

DOI: $10.1561 / 1100000053$. 



\section{Introduction}

"Running is my life. I will keep running to inspire the masses" says Fauja Singh in a recent interview after announcing his retirement from running marathons ${ }^{1}$ The surprising aspect of his statement is not so much the intention to quit running competitions but rather his age: Fauja is 102 years old and known as the oldest marathon runner of the world 2

What Fauja is teaching us is that life does not end after retirement and that the right exercise, diet, determination and opportunities have the power to keep or even improve quality of life also when facing the burdens of age. Fauja is not only an extraordinary sportsman, he is also representative of a more general phenomenon of today's ageing society (admittedly, an exceptional one): increasingly, people do not just live longer and generally healthier, but they also keep practicing physical activities (e.g., dancing, hiking or swimming), reading to stay informed or writing themselves to inform others, engage in social relationships (also over long distances), or travelling, even in advanced age. That is,

1 http://news.discovery.com/human/life/101-year-old-marathoner-retire-130124.htm

2 http://en.wikipedia.org/wiki/Fauja_Singh 
older adults are increasingly active and want to take part of society and to contribute to it.

Enabling this active participation as we grow old has become one of society's most important modern challenges. And this is a challenge with many sides. First, prevention of age-associated physical function decline and disabilities has gained importance and it has been pointed out that it should be the focus of society's attention [55, 70]. When older adults lose their ability to move within their environments without needing assistance they are less likely to remain active in the community. Second, as we age, our health is naturally challenged and older adults face higher rates of morbidity, mortality, health care utilization and cost, next to a poorer quality of life [68, 69, 73. Finally, with people living increasingly longer, our society is slowly changing its composition, adding to the complexity of the problem: the World Health Organization (WHO) estimates that "by 2025 there will be approximately 1.2 billion people worldwide over the age of 60 , reaching 2.0 billion people by 2050 , with $80 \%$ of them living in developing countries" 182 .

Addressing these issues involves perspectives as different as health sciences, economics and politics. In healthcare, the focus is usually set on increasing the amount of years of good health as the means for extending independence and quality of life as long as possible [155. Healthy ageing is characterized by the avoidance of disease and disability, the maintenance of high physical and cognitive function, and sustained engagement in social and productive activities [41. These three components together define successful ageing [140]. The challenge we are facing today is how to support public health policies that would help older adults in achieving the goals of prevention with the aim to remain independent. An extended life should ideally also involve preservation of the capacity to live independently and to function well [87. That is, we need to understand how to provide effective answers to the need for specifically tailored physical activities, how to provide intellectual stimuli that keep older individuals mentally active, or how to help older adults remain socially integrated; e.g. in touch with their family and peers. Here is where politics and public policy makers be- 
come important [142, who must recognize these needs and work toward an environment, a society and an infrastructure that facilitate life for older adults. Large support for public health policy can in this context also be allocated to technology in terms of advanced instruments for healthcare and in terms of support it can provide to the everyday activities of individuals. Technology is already permeating our everyday lives, e.g., smartphones and the Internet. Yet, many of the solutions are still targeting tech-savvy people and do not specifically focus on older adult users and their families or communities.

With this narrative review, our aim is to shed light on the role information technology (IT) might play in supporting older adults to age actively. Our goal is to understand how IT can better support an Active Ageing, which we defined as a physically, mentally and socially active lifestyle as a person ages. The review is based on the analysis of literature collected during two years of research and practice in designing IT solutions specifically tailored to the needs of older adults and includes contributions coming from Computer Science disciplines as varied as eHealth, Mobile Computing, Social Computing, Ubiquitous and Ambient Computing, Persuasive Technologies, and Human Computer Interaction; coupled with contributions coming from $\mathrm{Hu}-$ man Movement Sciences, Psychology, Gerontology and international institutions (e.g. UN and WHO) reports on the topic. We provide the following contributions:

- A review of the concept of Active Ageing in light of its different definitions in literature, followed by a discussion of the challenges and design issues of IT for older adults.

- A systematic evaluation framework that brings together the different determinants that affect quality of life during the ageing process with the support IT can bring to modulate these determinants.

- A review of literature including exemplary IT services and applications that provide support for Active Ageing, using our evaluation framework analyze contributions and describe their characteristics. 
- A discussion of the different aspects of the state of the art and an outlook of what we believe will be the challenges and opportunities of the IT solutions for Active Ageing to come.

The remainder of this article is structured as follows: First, we discuss the effects of age and the meaning of Active Ageing. Then, in Section 3, we analyze what contributions IT in general can bring to ageing and which are the core design challenges in doing so. In Section 4. we introduce our evaluation framework. In Sections 5, 6, 7, and 8, we present the core overview of IT services and applications we have evaluated, offering also a discussion at the end of each of these sections. In Section 9 we discuss the main limitations of our review and the related works that precede and have helped to shape our own. We conclude our review summarizing the discussions we present in each section and presenting an outlook of challenges and opportunities of IT for active ageing (Section 10). 


\section{2}

\section{What is Ageing?}

Ageing is a process we all undergo from the moment of our birth. At the beginning, ageing means growing, getting stronger, and differentiating ourselves while we build our identities, gain experience and knowledge. Around the age of 20, our physical, sensory, and cognitive capabilities peak and stabilize until we reach our 50s/60s. While our life experiences and our knowledge (and perhaps our wisdom) will continue to grow, our capabilities start to decline depending on factors like our genetics, lifestyle, and social environment. The exact reason of this decline is not yet entirely understood. Some theories speak of a natural and programmed process that takes place in our bodies, while others explain decline as the result of damage accumulated over time [63]. Independently of the reasons that determine decline, ageing unavoidably affects functioning as a complex interaction of genetics, chemistry, physiology, and behavior/lifestyle [161.

Ageing often comes with augmented risk of adverse health conditions that may affect physical and cognitive functioning. Some of the most common age-related health problems are mobility and/or cognitive related. Sometimes the changes in physical capabilities come as a result of diseases. Non-communicable chronic diseases increase in most 
societies [89] and negatively effect on physical and cognitive functioning. Examples of non-communicable diseases are diabetes, cancer, and hypertension. Most of the health problems in old age are chronic noncommunicable diseases [182], which require constant monitoring and care. Although research has shown that many of these conditions have their origins in early childhood, it is well known that behavioral factors; e.g., tobacco or alcohol consumption, a sedentary lifestyle, etc. considerably increase the risk of developing or aggravating non-communicable diseases. The likelihood of suffering cognitive decline or developing dementia increases with age [71] and is, furthermore, related to noncummunicable diseases [34, 47, 98. The extent of usual age-associated cognitive decline - a.k.a. normal cognitive ageing - differs in extent between individuals [44]. Some of the aspects of age-related cognitive decline already begin in healthy educated adults when they are in their 20s and 30s [141]. There is growing appreciation, however, that factors affecting general bodily ageing also influence cognitive functions in old age [44.

Independently of health, there are three macro-areas of manifestations of age that group different phenomena that affect quality of life and that allow us to structure our analysis: physical capacity, i.e., the capacity to perform physical activities; sensory capacity, i.e., the capacity to capture and interpret information; and cognitive capacity, i.e., the capacity to process, reason on, and produce information. Common cardiovascular, neuromuscular, physiological, sensorimotor, and cognitive changes associated with ageing are summarized in the literature [36, 100, 119]. It is worth noting in this context that social, mental and physical lifestyle components may also beneficially effect on cognition and dementia [58].

Research has also shown yet another key aspect of ageing, one that is sometimes disregarded or not mentioned when discussing the phenomena: our ability to still grow in happiness. In fact, there seems to be an increase on self-reported subjective wellbeing once we pass our 50s [163. Research findings related to emotional aging suggests that many older adults enjoy high levels of affective well-being and emotional stability into their 70 s and 80 s, which is contrasting the observable cogni- 
tive and physical decline due to aging [145]. These advantages of older adults in the emotional domain are, when considered to improve cognitive interventions, effective to improve quality of life [145] and physical activity behavior [128].

Of the different aspects that are related to happiness in one way or another, a dominant aspect seems to be how satisfied we feel with people that we like, spending time with them. Happier people have more social support and social connectedness [160] and there are also hints pointing to social connections and engagement as one of the key factors for longevity in some of the so called "blue zones" (places where people live to 100 years) [23. Subjective well-being is strongly linked (both directly and through its impact on health) to social capital (i.e., strength of social ties) [75] and both to our family and social networks structure [171]. Supportive interactions have also good effects on health measures, like the functioning of cardiovascular system [172].

This duality of ageing, where we can grow in some aspects (i.e., experience, wisdom, happiness) and yet face also decline in others (i.e., physical, sensory and cognitive abilities) is what takes us to the concept of Active Ageing, which we discuss and define in the following section.

\subsection{What is Active Ageing?}

Ideas around Active Ageing have taken many different names and forms within the field of Gerontology. The WHO popularized Active Ageing by publishing a policy framework for enabling it. WHO's definition emphasized opportunities within the process of ageing, with Active Ageing being the "process of optimizing opportunities for health, participation and security in order to enhance quality of life as people age" [182]. Also the United Nations, through its Economic Commissions for Europe (UNECE), provides a definition that emphasizes that the promotion of social integration and active involvement in community are the key elements of Active Ageing [173]. Autonomy, self-determination and choices are the core dimensions according to [112] and the Institute for Prospective Technological Studies of the European Union (IPTS) emphasizes the need for policies around independence and au- 
tonomy [111, defining Active Ageing policies as those that "enable people, as they grow older, to lead independent lives (socially and economically), making their own choices about how to shape their lives in all its spheres".

In 2012 the European Union (EU) promoted the European Year for Active Ageing (http://europa.eu/ey2012/) updating the definition of Active Ageing to "growing old in good health and as a full member of society, feeling more fulfilled in our jobs, more independent in our daily lives and more involved as citizens". The EU takes a more lifestyle oriented definition, which is summarized in a particularly inspiring phrase from their website: "No matter how old we are, we can still play our part in society and enjoy a better quality of life". Employment, Participation and Independence are the key dimensions in this definition.

In summary, the general idea is that it does not matter how old you are, there will still be a role to play in society to enjoy a better quality of life. Whether we define it from a policy-making perspective or from a lifestyle point of view, Active Ageing improves wellbeing in the dimensions of health, participation, security, employment, independence, autonomy and integration. All these dimensions can be argued to be included within those proposed by the WHO, leading to the definition we used in this survey, where we put together both policy makers and the lifestyle perspectives.

Definition 2.1. Active ageing is having a physically, mentally and socially active lifestyle as we age, with optimized opportunities of quality of life in the domains of health, participation, and security.

"Health is a state of complete physical, mental, and social wellbeing and not merely the absence of disease or infirmity" [183]. Participation is the ability of a person to engage in socio-economic and cultural activities, making a productive contribution to society as they age (e.g. attending cultural activities, volunteering, being part of local communities, interacting with family and friends). Security is having adequate protection and care when assistance is required while maintaining as much as possible of autonomy and independence (e.g. receiving quick response to emergencies such as falling, or having the 
possibility to make our own choices). Altogether, these are the three main aspects of Active Ageing and they influence each other in multiple ways [120, 177]. Health is often seen as a precondition for participation and security, however, it is also well know that more social participation can improve health, while at the same time security can enhance people's opportunities for participation [168].

\subsection{Determinants of Active Ageing}

How well both individuals and populations age is determined by a set of enabling factors (and the interplay between them) called the determinants of Active Ageing, each affecting one or more of the three main aspects of Active Ageing we presented before.

Definition 2.2. Determinants of Active Ageing are influences that surround individuals and which the process of Active Ageing depends on.

Based on the report by the WHO [182] and other inputs from the literature we have cited in the previous section, there are 17 determinants that are key for enabling Active Ageing, organized in six main categories. Building upon WHO's definitions, each of these categories is explained in the following paragraphs. A description of each specific determinant is included in Appendix A.

Health services are public or private health services to which a person has access, including health promotion, disease prevention, curative and mental health services. Part of this is the equitable access to primary healthcare and long-term care by informal caregivers and/or healthcare professionals. Behavioural determinants are the behaviours a person regularly follows. Behaviours like healthy nutrition, active participation in ones own care, not smoking nor using alcohol and engaging in regular physical activity can all have a positive impact on Active Ageing. Personal determinants are the set of characteristics of a person's biology, genetic and physical limitations, including psychological factors like ones own intelligence, cognitive capacity, selfefficacy and self-esteem. 
Environmental determinants are the conditions of a person's physical surroundings which can help people age better. Transportation means, safe housing, clean water, air and safe food are all environmental determinants of Active Ageing. Social determinants are the conditions that define a person's social environment, including how much support a person receives from its social networks, how many opportunities for education and lifelong learning the person has access to and how much risk of violence and abuse the person is subjected to. Finally, economic determinants are the set of different aspects of an individual's economic environment like level of income, access to work and to social pension (also referred to as social protection) services.

Altogether, determinants influence the process of Active Ageing by improving or deteriorating the opportunities for Health, Participation and Security. They can be seen as the general categories of problems that must be solved in order to enable an Active Ageing. The role that IT can play is that of attacking the problems that are hidden under each of these categories, so that in the end, opportunities for health, participation, and security are improved. In Europe it was the European Commission that identified active and healthy ageing as a societal challenge common to all European countries. Active ageing and independent living ${ }^{1}$ is one of the pillars around which actions are focused [35. The specific action proposed to address issues related to this pillar is to develop ICT solutions to help older adults stay independent, more active and mobile for longer [66, 184, 185].

\footnotetext{
${ }^{1}$ See http://ec.europa.eu/research/innovation-union/index_en.cfm? section=active-healthy-ageing
} 


\section{3}

\section{IT for Active Ageing}

IT can help to maintain health and independence, increase participation, and enhance security as we grow old. To do so effectively, it cannot overlook the changes that ageing brings to people's lives. Before we enter a detailed account of IT applications and services that enable an Active Ageing, this section explains the four approaches by which IT can do so, and it presents also a small review of the challenges ageing pose to IT design.

\subsection{Objectives of IT for Active Ageing}

The four approaches in which IT can enable an Active Ageing come from the literature of Gerontechnology, an interdisciplinary field devoted to "the study and design of technology and environments for independent living and quality of life of older adults' 1 . These four approaches are summarized as Gerontechnology goals [74]. Figure 3.1] shows our representation of each of these approaches in terms of how they positively impact in some aspects of our life. In each figure, the

\footnotetext{
${ }^{1}$ http://gerontechnology.info/index.php/journal/pages/view/isghome
} 


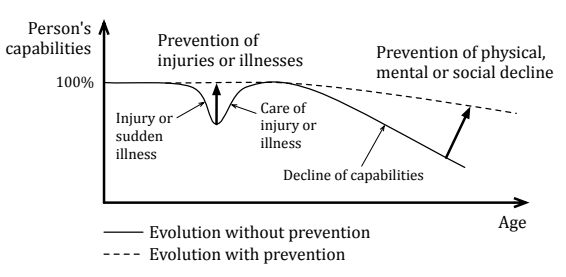

(a) Prevention and care of injuries or illnesses

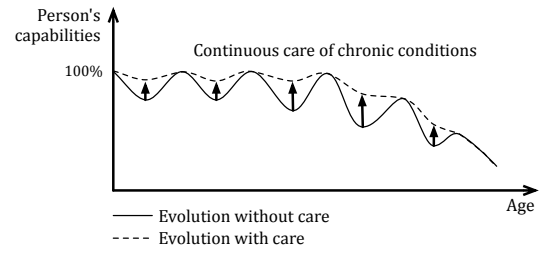

(d) Care of chronic conditions

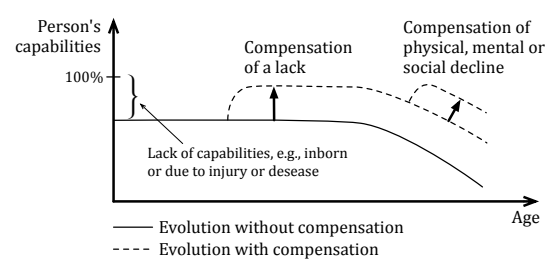

(b) Compensation

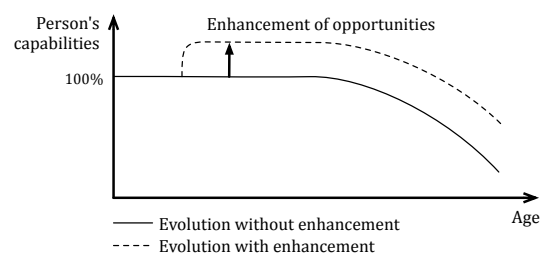

(d) Enhancemenent

Figure 3.1: Gerontechnology Goals

dashed curve represents how would our life course be by following these approaches. A definition of each goal follows the figure.

- Prevention. Is the first and foremost goal of Gerontechnology. Successful prevention can make the other three goals redundant. In addition to enabling an Active Ageing, prevention implementation success may also lead to economics savings that can be redirected to other societal needs [74]. As we age, prevention helps us to avoid injuries and slow down physical, mental and social decline (Figure 3.1 a). Using a machine to stay fit and keep walking, following a physical training plan using videos on YouTube, improving our nutrition with a tool that helps us log and monitor what we eat or stimulating our brain with computer games are examples of IT enabling Active Ageing through prevention.

- Compensation. When an impairment or disability can no longer be prevented or cured, compensation comes into place to either reduce the impact of the declined capability, or to partially and artificially replace a not available capability (inborn or due to injuries or illnesses; Figure 3.1b). Compensation is applied either on the environmental or on the personal level [74]. (Geron)technology 
can be used for these purposes, making up for impairments that people face as they age.

- Care. When we cannot prevent nor compensate a problem, and/or we need assistance to recover from an incident or to reduce the impact of a chronic condition, care is needed (Figures 3.1 and 3.1k). (Geron)technology for care acts to facilitate the work of the caregivers. The caregiver can either be a formal caregiver (e.g., nurse, physician) or an informal caregiver (e.g., family member, friend).

- Enhancement. (Geron)technology can help to create new opportunities and extent existing capabilities, and help people gain new capabilities (Figure 3.1 d). Using IT to keep updated with our interests, to learn new things, to find interesting activities to join, to augment experiences in which we are already involved, to enable real time access to information or to discover new experiences or work opportunities that we can commit to are examples of IT for enhancement.

\subsection{Challenges of IT Design for Active Ageing}

Most of the literature we have used to construct this review, relies on ideas and requirements for design that follow the tradition of accessible design [126], by which the specific needs of older adults are considered in the design. Although describing this tradition escapes the goals of this review, we include a summary of the most common design considerations we have found in literature as a way of setting some context around what guides the design of the ICTs we describe in this review. There are, however, some critiques to this tradition, mostly noting that too much focus on accessibility and limitations can lead to the development of stigmatizing solutions that segregate users [164], and that it should be replaced by a more universal design [108] approach that focuses on solutions for an age-diverse population that do not overtly suggest any specific age. In particular, following guidelines that target reducing the complexity and overload of user interfaces, prioritizing 
simplicity and intuitiveness, are in line with this latter, more processoriented [80, approach that can actually improve the user experience of everyone, regardless of their age.

To start with this short summary of guidelines, we first consider how to cope with age related physical impairments. A solution may come from the interface device used to interact with technology. For example, impairments that are associated with manual dexterity make it harder for older adults to perform tiny movements with the mouse or a touch pad [143]. For this reason, touch screens have been shown to be better suited in reducing usage barriers and avoid frustration [95. Touch screens, and in general direct manipulation interfaces, might increase user satisfaction, reduce anxiety of using computers, are easier to use and increase speed of tasks completion [133]. Multi touch gestures, however, might increase difficulty and must be carefully designed [165]. Moreover, most touch screens are capacitive, i.e. they react to electrical charges in our fingers, which is in turn affected by blood circulation. Because of age-related decrease in blood circulation, it might also be the case that some touch devices require better sensitivity [117.

Second, to cope with sensory impairments, the considerations are often related to the visual user interfaces. Sensory impairments interfere in the way people hear, see, and touch things. To cope with vision problems dark backgrounds should be avoided as well as small fonts, similar text and background colors, complex font styles, and distracting colors or pattern backgrounds [13]. Because of lesser contrast sensitivity, the use of complementary colors (i.e. colors in opposite sites of a color wheel) is recommended. Large, easy to read text, with high contrast is another common recommendation, which goes along with limiting the amount of information on screen, both of which can improve visual search efficiency and attention [13, 118, 133. Regarding hearing impairments, high frequency sounds should be avoided for alarms and alerts, since older adults cannot properly hear them. Because of the reduction of spatial acuity of light touch, small buttons, links, and keyboards, as well as a short distance between navigation buttons, are discouraged. 
Third, coping with cognitive decline usually implies careful design of user interfaces in ways that reduce complexity. Keeping simple grammar structure, avoiding implicit text and messages, and technical expressions are ways to achieve this. In addition, the information should be presented slowly, so that the old person has enough time to read and process. Older people with and without previous computer experience place much more importance to words than icons in their everyday interactions with the web [143]. Clear structure of tasks and consistency of information are additional important requirements to reduce complexity and cognitive load. Key function unity (i.e. one key one function), page function unity (i.e. one page one function), the use of wizards for complex tasks, coloring and labeling information, navigation bars or menus and consistency of user interfaces across software versions are some guidelines to achieve this [133]. The need for quick answers and reactions from the user should be avoided; on the other hand the feedback from the system must be rapid, continuous and distinct to help the users in understanding where they are.

The learning process is also part of interacting with technology. It is usually recommended to go slow, allocating enough time to internalize and, if possible, memorize all the new information this process entails. It is important to offer context information about the learning subject in order to cope with memory loss. Constantly available instructions written in a non-technical language are highly recommended [127.

For a more detailed account of design guidelines and considerations, see the book by Fisk et al. [56], among many others [31, 40, 130]. Similarly, another source for these considerations are the design guidelines produced by organizations like the The John Gill Technology Institute (http://www.johngilltech.com/guidelines/) or the US-based American Disabilities Act (http://www.ada.gov/). We also suggest to consider the literature on universal design, which includes for example the handbook by Preiser and Ostroff [134], the original book by Mace et al. [108, and many others [80, 159, 164.

The real challenge of design for active ageing lies on balancing both accessible and universal design in a way that helps technology in responding better to the needs of the ageing population, without stig- 
matizing them nor overly focusing on the limitations side. Other than compensating and supporting care, ICTs can also play a role in preventing decline and enhancing life with new opportunities. 


\section{4}

\section{Evaluation Framework}

The goal of this review is to understand how IT can aid people in achieving the goals of an Active Ageing, that is, which IT solutions may help address which of the problems related to helping people to reach these goals. We therefore developed a conceptual evaluation framework that brings together the two perspectives introduced above. The structure of the framework is illustrated in simple terms by Figure 4.1. On the the top (the problem domain), we find our definition of Active Ageing, with its three major dimensions (health, participation, security). In order to understand how IT may modulate these dimensions, we then show which determinant categories (and their specific determinants described in Appendix A) can be used as levers. From the bottom (the solution domain), we structure the solution space first into the four goals (we could call them also application domains) technology may pursue, in order to make life better; then, we show which types of applications may serve which of these goals. The combined structure of the framework, with the connections we have found in our review, is fully illustrated in Figure 4.2

The types of applications are a bottom-up result of our analysis; in section 4.1 we describe the body of works considered and the criteria 


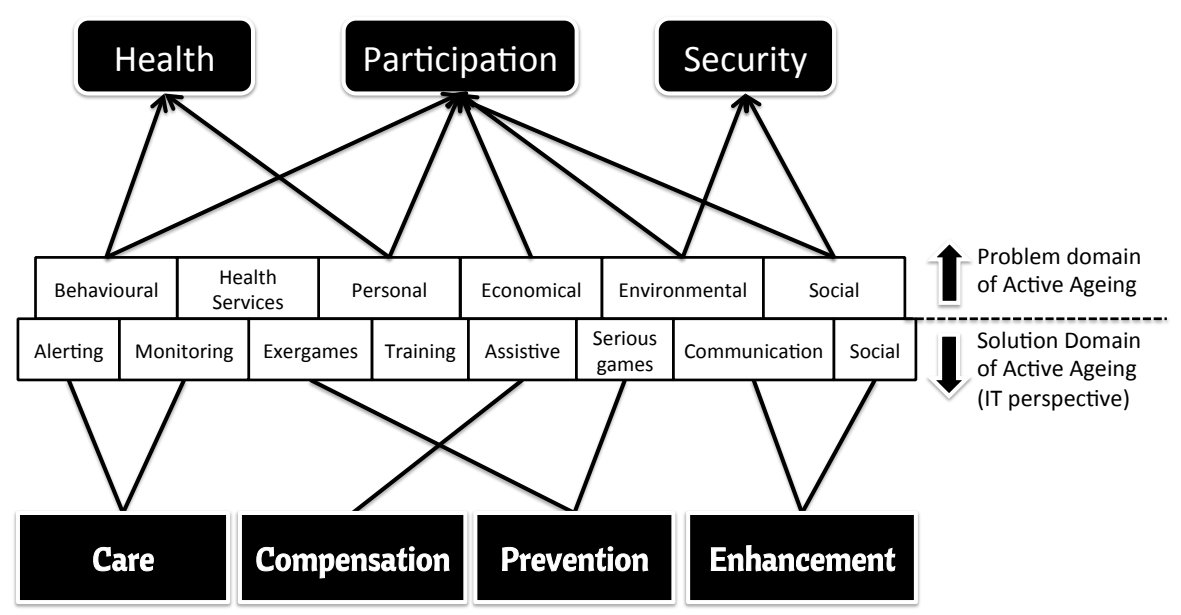

Figure 4.1: The Problem and Solution (IT perspective) Domains of Active Ageing

we followed for their selection. The application types stem from a careful clustering of all considered applications into groups of applications serving similar purposes; clusters were considered only for groups with at least three members. Applications of the same type share common features, such as monitoring physical activities, gaming, alerting about medication, and similar. Given the versatility of applications and the different uses one may make of them, one application may fit into one or more different types. However, in order to assign each application to exactly one type of application when multiple options were available, we opted for the type in which most features of the application were focused. For example, alerting applications generally include the features of monitoring applications (e.g., tracking some metric of measure), in that they add additional functionality to their features (e.g., rules that fire if a measure exceeds a given threshold and notify a caregiver or family member).

The types of applications we identified are:

- Monitoring applications are systems that keep track of the state of something or someone (e.g., activity sensors like wearable step counters or pedometers). 
- Alerting applications are systems that notify about the occurrence of an event (e.g., medication reminders).

- Assistive applications are systems that help users in the realization of an activity by suggesting how to perform the activity (e.g., interactive mobility or activities of daily living - ADLs guides).

- Training applications are systems that guide someone to improve a particular skill over a period of time (e.g., nutritional virtual coaches).

- Exergames are serious games that have physical exercise as a primary purpose (e.g., Nintendo Wii fitness games).

- Serious games are games whose primary purpose is solving a problem, not pure entertainment (e.g., cognitive stimulation games).

- Communication applications are systems that enable remote peers to communicate (e.g., person-to-place texting services).

- Social applications are systems that enable social interaction and networking (e.g., social networking services).

- eLearning applications are systems for electronically supported learning and teaching (e.g., Web knowledge and wisdom sharing sites).

As illustrated in the framework picture, the role of application types is not merely that of classifying applications, but, more importantly, that of connecting the determinants of Active Ageing with the four gerontechnology goals and of explaining which type of application may be used to act on the determinants and to implement which goal.

In order to facilitate the comprehension of what characterizes applications for Active Ageing, we identify seven major dimensions to further analyze each application: 


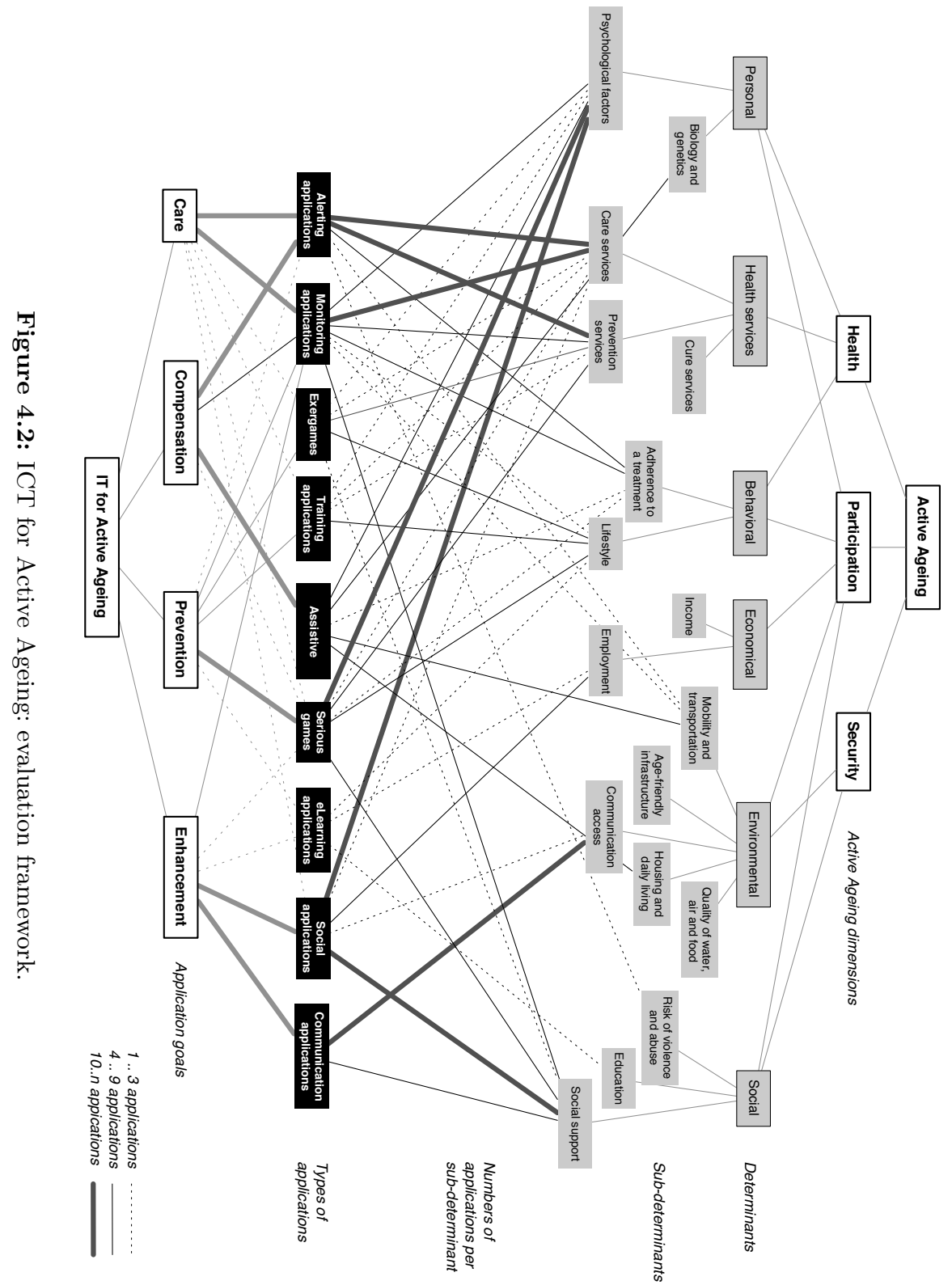


- Stakeholders: These are the people who interact with the application. We distinguish three types of stakeholders: the beneficiary; the family, including informal caregivers and friends; and the healthcare professional, which includes formal caregivers (e.g., doctors) and generic healthcare experts (e.g., physiotherapists).

- Beneficiary: This is the most important stakeholder, typically the older adult, that benefits from the application. Examples of beneficiaries are independently living or community-dwelling older adults, older adults following a treatment, under informal or formal healthcare, with physical or cognitive impairments, and similar.

- Intrusiveness: This refers to how much an application represents an uncomfortable obstacle to the normal life of the beneficiary. Examples of potentially intrusive elements are storage of private information, frequent requests to interact with the system, reminders or alerts, the need to wear or carry a device or sensor, and similar.

- Risks: These refer to the potential harmful consequences or damages in the case the application or device does not function properly. Examples of risks are physical injuries, negative emotional impact, or leak of sensible information, and similar. The higher these risks, the lower the potential adoption.

- Collected data: These refer to the information that is captured, processed and/or stored. Typical examples of collected data are: a person's performance in a physical or cognitive activity, medication prescriptions, adherence to a treatment, etc.

- Persuasion techniques: These are the techniques that aim to keep the motivation to use the application high. Examples are: gamification, competition, collaboration. The full list of persuasion techniques we consider is provided by Fogg [57].

- Infrastructure requirements: These include the hardware, software and infrastructure requirements of the application, such 
as: $P C$ (e.g., desktop computer, laptop), game consoles (e.g., Nintendo Wii, MS Kinect), touch/gesture devices (e.g., tablets and tabletops), and custom-made devices (e.g., medication dispensers, vests), and similar.

We use these dimensions in the following analysis, which we structure into four sections, one for each of prevention, compensation, care, and enhancement.

\subsection{Literature Selection}

The review presented in this article is based on a dataset of about 150 references, which we collected over the last two years to understand how IT can help achieve the above four gerontechnology goals, i.e., prevention, compensation, care and enhancement. Given the strongly multi-disciplinary nature of the research on technologies for Active Ageing and the fast evolution the field is undergoing, we did not limit our analysis to a pre-defined set of conferences or journals and instead opted for an "open" approach that considers (i) mature scientific conference and journal contributions as well as (ii) research prototypes and products that can already be found on the market. The former include contributions coming from Computer Science disciplines as varied as eHealth, Mobile Computing, Social Computing, Ubiquitous and Ambient Computing, Persuasive Technologies, and Human Computer Interaction. The latter were identified via the literature review, Web search, and via face-to-face discussions with IT researchers and healthcare providers working on Active Ageing. 


\section{5}

\section{IT for Prevention}

We start our review of IT applications and services for Active Ageing with those that help people to prevent (or delay as much as possible) age related physical and cognitive decline.

\subsection{Applications for Prevention}

The first approach to prevention from the IT perspective is the use of exergames to motivate people to participate in positive and healthy activities. Most exergames are designed to prevent physical decline by helping and motivating older adults to engage in physical activities, maintaining and even improving physical abilities such as muscle strength and balance. Gaming consoles that allow players to control games with their movement favour the development of these systems. For example, many of the games available for the Nintendo Wii console have been tested with seniors in several studies [94, 96], almost always with positive results in terms of acceptance of the technology and increase of physical activity. There are also efforts to improve the design of these games to make them even more suitable [60]. In this line, SilverPromenade [61] is an exergame specifically designed to mo- 
tivate institutionalized frail older adults (e.g., living in assisted living facilities), into taking virtual walks by easily stepping on and off the Nintendo Wii's balance board (i.e., a board similar to a weight scale that serves as a game controll for the Wii). In this way, the games can facilitate prevention services focused on maintaining good levels of physical activity, which in turn influence positively the lifestyle determinants. To a lesser extent, also Microsoft's XBox 360 Kinect console which does not need a remote sensor but instead uses a 2D camera, has been tested with success to, for example, stimulate visual performance of institutionalized older adults with wheelchairs [33]. According to Jung et al. [83, exergames in groups can also enable an Active Ageing by improving psychological factors like self-esteem and affect.

Other than game consoles, physical training often demands for custom-built devices and sensors. For example, de Morais and Wickstrom 42 have used a custom-built device with a camera and body sensor to record movement of a person in order to monitor and guide him or her into exercising through Tai Chi. By learning Tai Chi, the beneficiary will also improve physical abilities, positively affecting the lifestyle determinant. Similarly, a custom-built walk-board is used by Kim et al. 92 to encourage older adults to walk more by detecting when they are walking over it and giving incentives to do it again. The incentive is implemented by using the metaphor of a "virtual sheep" that they have to take care of within an animated farm, displayed in a PC. The more they walk, the better the situation of the sheep. Also for walking, Hansen [72] developed a custom-built robot that plays with people in a ball game where the ball is exchanged between both of them while the robot is moving. Seniors playing the game have to hand the ball back to the robot, which push him or her to walk. Walking more, in these examples, results in a positive impact on the lifestyle determinant.

Mobile devices have also been leveraged for exergames. This is the case of "Walk 2 Win" 121, a mobile game that older adults can play in group or individually and in which to progress, they need to walk in a closed environment and discover hidden artifacts. The application uses a smartphone and local Wi-Fi to detect the user's geographical location 
and a central server to synchronize and moderate the game. By simply playing, people increase their walking and socialize at the same time, positively affecting lifestyle and social support determinants.

Similar to exergames, the second approach to prevention involves the use of serious games that require the user to do a serious task while playing a game. Most serious games follow the goal of stimulating cognitive functioning skills (i.e., vigilance, visual-spacial attention, selective attention, focused attention, divided attention, handeye coordination, memory, etc.), positively affecting psychological factors determinants. One example of such games is the simplified version of Stepmania ${ }^{1}$ for iPads 52 designed specifically for older adults to play with and improve their divided attention abilities. Stepmania is a musical game in which a group of floating symbols falls through the screen, synchronized with a background music. The goal of the game is to catch the symbols just when they overlap with their corresponding button on the screen, by tapping on the buttons. Because the game requires concentrating on multiple moving object at the same time it can improve divided attention in the long run. Cogniplus [146] is another example with the same goals and wider range of cognitive training programs, deployed on a custom-built computer for animated cognitive games known as the Vienna Test System (http://www.schuhfried.com/vienna-test-system-vts). Cogniplus is used by psychologist in formal therapeutic environments, hence potentially improving health prevention services. Similar to Cogniplus, Posit Science (http://www.brainhq.com/) offers a wide range of brain training programs, which have been proven to succeed to some extent [8].

Also in the line of improving prevention services and psychological factors, tabletop devices (situated touch displays on a table) are also a popular platform to deploy serious games for seniors. Two examples are the HERMES Maze [24], used for training memory and preventing older adults from missing medical appointments; and an adaptation of the popular puzzle game Tangram [190], used to support psychomotor activity therapies. They both leverage on tabletop devices to offer a

\footnotetext{
${ }^{1}$ http://www.stepmania.com
} 
range of cognitive training games (e.g. puzzles, crosswords, mazes) that emulate the experience of playing a physical table board game, where seniors sit around a table and play together. The tabletop Tangram uses also a webcam to monitor game playing in order to detect mistakes and train the user in solving the puzzles, with the goal of improving short and long term memory.

More in the line of improving lifestyle determinants, mobile devices have also been used to deploy serious games. An example of this is OrderUp! [67], a mobile game that runs on a smartphone and puts the user in the role of a server in a restaurant whose goal is to make meal recommendation as quickly and healthy as possible, in order to keep the job. The more healthy the choices, the more health points the user gains. Ultimately, the goal is to motivate people to consume healthy food. Since a small social network is integrated in the system to discuss nutrition choices, there is also a positive impact in the social support determinant. Similarly, Derboven et al. 45 designed a shopping game where older adults have to remember the shopping list and buy the products in a virtual reality shop. The family can connect to the game too, in which case they assist players with the shopping. This practice improves memory skills, adding psychological factors to the list of determinants that are positively affected by this system.

The third approach to prevention is the use of training applications with the purpose of preventing decline or loss by training an ability or skill. These applications benefit from incorporating persuasion techniques but without making the training into a game like serious and exergames do. An example of this type of applications is ActiveLifestyle [155], an iPad based training application that provides video-based training exercises to improve strength and balance. The application also incorporates persuasive strategies (i.e. positive and negative reinforcement, social interaction with public bulletin board and private mailing system, collaborative training, self-monitoring and reminders) in order to motivate the user into adhering to the training plan. Similarly, Flowie 1 is a training application for motivating older adults to walk. Flowie keeps track of the daily step count of the person with a pedometer and displays progress using growing flower in a 
situated display placed in the home. A third example of the same type is Seniorcize (http://www.walkinglibrary.com/seniorsize.html), a tablet application that presents workout sessions and tips about physical exercises. By supporting and motivating physical exercises training, all these applications positively affect the lifestyle determinant.

In the same line, also affecting positively the lifestyle determinant, and leveraging the use of sensors, Steffen et al. [158] designed an application to suggest physical exercises and monitor the user activity through a wearable sensor, thereby coaching the user throughout the exercises. Other works have used robots as trainers, which is the case of "robot exercise instructor" [53, a mobile robot that coaches the user to perform seated exercises to improve physical strength. During the training, the robot performs the exercise activity and the trainee imitates the robot. Training applications addressing the lifestyle determinant are not only about physical activities. DanceAlong [88, for example, is a training application for learning how to dance. Focused on nutrition, Autom [22] is a small robot that helps users to improve their nutrition and prevent health problems through a conversational system that engage older adults in a daily coaching dialog about nutrition. Products like the FitBit (http://www.fitbit.com/), Nike Fuel Band (http://www.nike.com/us/en_us/c/nikeplus-fuelband) or the Jawbone (https://jawbone.com/) are commercial examples of these types of sensor-based systems to support the improvement of lifestyle through physical training.

Finally, one last example of training application is CleverMind (http://www.myclevermind.com), an iPad application with a nice and intuitive interface specifically designed for older adults with decreased cognitive ability that features cognitive assessment training, tracking and reporting integrated within all the other functions of the tablet like surfing the Internet or connecting with loved ones through facebook. The goal is to entertain users while at the same time strengthening their cognitive proficiency, positively affecting psychological factors and social support.

The fourth approach to prevention is the use of monitoring applications that monitor user's behaviors, sending this information to 
third party who can response to it in preventive manners. Most of these applications affect the prevention services and care services determinants, because they improve the connection of older adults with their caregivers. For example, the nutritional advisor system [97] allows nutritionists to create a menu and a diet schedule for an older adult, who can later report about his or her compliance with the diet. This can have a positive impact on the lifestyle determinant. Similarly, but focused on cognitive testing, Byun and Park [25] designed a monitoring application that keeps track of several metrics for an older adult user (e.g., reaction-time, short-term memory, discernment) in three different cognitive games, informing about this performance to the beneficiary's doctor. The doctor can then use this information to assess his or her psychological wellbeing with the goal of planning interventions or adjust therapies. The same approach is proposed for Alzheimer's interventions [110] and for other services to asses cognitive state of elders [81, 82 in order to support prevention services. Playing games within these applications have also an additional positive impact on the elder's psychological factors.

Another monitoring application to support care and prevention services that is mixed with a game consists of a system to monitor seniors' performance in following the instructions correctly when playing Dance-Dance-Revolution (a dancing game where a person receives dancing instructions and needs to move accordingly) [157]. The person's movements are monitored through a sensing carpet and a score is presented at the end of each music allowing caregivers to monitor dancing movements and assess patients physical conditions. This, in turn, is used to support training advices or to adjust the physical training program that serves the purpose of preventing physical decline, thereby also addressing the lifestyle determinant.

In some cases, a self-monitoring approach might be enough to improve lifestyle. For instance, Consolvo et al. [37] provides a fitness device that allows older adults to monitor their own physical activities and sends the data to their phone to support user self-awareness about his physical conditions. Another self-monitoring application worth mentioning is the Iom feedback hardware (http://www.wilddivine.com) 
consisting of a wearable sensor that measures "skin conduction level" as a measure of stress, and later guides the person, through a PC application, in how to control and reduce stress, addressing then the psychological factors.

To a smaller extent, prevention is also enabled by the means alerting and eLearning applications. Alerting is used to inform the elder or a caregiver in a potentially harmful situation right away, trying to prevent them from happening. An example is the Ambient Trust Cube [151] consisting of a custom-made light cube that visually alert older adults when they try to visit a risky website (using a definition of risky websites provided by the WebTrust - http://www . webtrust.org), thus preventing potential risks of violence and abuse that might result from these websites. On eLearning, Ali et al. [2] designed an application that organizes nutritional knowledge in modules that are easy to use by older adults, helping them to gain awareness of their nutrition to prevent health problems, thereby addressing the lifestyle determinant and positively affecting also education.

\subsection{Discussion}

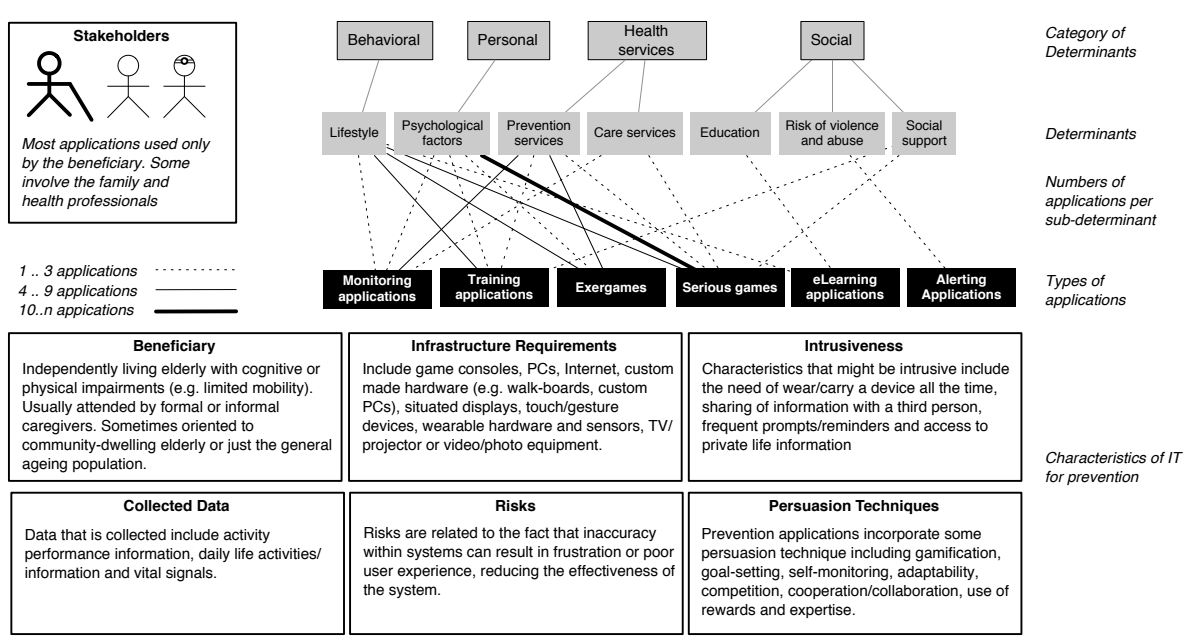

Figure 5.1: Typical characteristics of IT solutions for Prevention 
Prevention applications aim to prevent a decline. This can be physical (e.g. strength and balance), cognitive (e.g. memory, attention and vision) or even social (e.g. social isolation). Hence, accuracy (e.g. accuracy of collected data or functioning of the application or device) is important, since the lack of accuracy does not seriously hurt the beneficiary. This, along with the facts that games are motivating and simply fun, are strong reasons of why most of the applications in this section are exergames and serious games. In this regard, Nintendo Wii and MS Kinect are frequently used as an instrument to deliver exergames for older adults. However, most cognitive training games and applications use a cheaper device such as a personal computer or a tablet. Given that physical training games require the beneficiary to perform physical activities, exergames using Wii and Kinect can fulfil this requirement. Cognitive training games usually require an interface with controls (e.g. keyboard, mouse, touch interface) to supply the training program. Bearing in mind the lower demand for accuracy and the beneficiary of prevention application (which is considered as a healthy elder with limitation) games are a very good choice. Another reason for serious and exergames to be so popular in prevention is that they were very successful to increase the adherence of a preventive activity.

Monitoring applications are also widely used for the purpose of prevention because they are useful to keep the healthcare experts updated about the beneficiary's situation and eventually allow the experts to control the beneficiary's behavior. Monitoring applications oftentimes enable healthcare experts to take decisions about the beneficiary's healthcare and to prescribe a more accurate intervention based on the beneficiary health. Hence, most of these applications target more that one user category. It is usually the beneficiary itself and the healthcare experts or family that controls the monitoring part. Among these, fewer monitoring applications do not involve a third party and instead provide self-monitoring to the beneficiary.

Training applications incorporated with persuasion techniques are also very common, particularly in serious training scenarios, where professionals are behind the training programs that are facilitated by the systems. Gamification is also widely used in most of the training appli- 
cations in addition with other persuasion strategies (e.g. positive and negative reinforcement, self-monitoring, and awards) to motivate older adults into maintaining adherence to the training plan.

The rest of the applications (i.e., alerting applications and eLearning) are rarely used for the purpose of prevention. In prevention, alerting applications are acting similar to self-monitoring applications by reminding the beneficiary about potential risk or threat that might happen. It is notable that very few applications used eLearning in order to prevent a physical or cognitive decline by teaching the beneficiary exercises that changes their lifestyle to a more active one. Unlike the aforementioned applications, eLearning is using an indirect way to prevent the beneficiary from a wrong lifestyle or activity.

Based on our analysis, prevention applications are usually not too intrusive and tend to be cheap since they often-times do not require high accuracy and a complex custom-built system. Lack of accuracy in these systems however might hinder the user experience and lead to frustration with the technology. Intrusive characteristics might include in some cases the need of carrying or wearing a sensor (i.e., a pedometer to count steps). In general, natural user interfaces such as tablets and tabletops are very common, providing direct interaction with the objects on the interface.

Furthermore, prevention seems to be the most important area where game mechanics and persuasion technologies can find a successful application domain. In fact, they are already in use within many of the contributions for prevention we have included in this review, showing effectiveness in improving, for instance, adherence to training plans [1, 155.

Figure 5.1 presents this summary visually, highlighting the connections between Active Ageing determinants and the types of applications that affect them along with their aggregated characteristics. 



\section{IT for Compensation}

When an impairment or limitation can no longer be prevented, IT enables Active Ageing by compensating the reduced ability. In this section, we describe IT contributions that fall under this category, including assistive, alerting, monitoring, serious games and social applications.

\subsection{Applications for Compensation}

The first way in which IT contributes to compensating the impact of a reduced or lost ability is by assisting people in activities where the affected ability is involved. We refer to this type of contributions as assistive applications. A system that is exemplary of this approach is MAPS (Memory Aiding Prompting System) [30], which helps to compensate memory limitations while performing daily life activities like taking a bus to reach home or shopping groceries for a meal, addressing thus determinants of psychological factors, housing and daily living and mobility and transportation. MAPS uses a PDA (i.e., personal digital assistant) to prompt a person what to do in order to complete an activity, one step at a time. The list of steps to follow (i.e., the assis- 
tance script) is previously prepared by caregivers, loaded in the PDA via wireless networks and triggered manually by the person who selects what activity to perform or automatically by the PDA which suggests what to do. MAPS can also integrate information from a public transportation system and GPS in order to provide a real time personal travel assistant. The guidance provided by MAPS has been found to be effective on increasing independence of its users, who were also able to follow instructions, although not always in a precise way [29]. Addressing also housing and daily living and mobility and transportation but without focusing on psychological factors, the Information Bubbles system [78] also provides assistance information in a PDA, only in this case the prompts are automatically displayed when the elder is inside a "bubble" (i.e., usually visited buildings like the town hall or the supermarket) and contain guiding information about that place (e.g., where specific products of the supermarket are). iGrocer [152] is a smartphone assistive application that advises users what to buy, what to avoid and where to find products in the supermarket, based on a nutritional criteria that is previously established to respond to the user's particular health conditions or needs, addressing the determinant of housing and daily living.

More focused on mobility and transportation and psychological factors, Fujitsu's Smart Walking Stick (http://www.bbc.co.uk/news/ technology-21620624) compensates forgetfulness by embedding an assistive application in an everyday common object used by many older adults: their walking canes. The cane has a GPS sensor locate the person, a LED display mounted on top to show what direction should be taken, and it vibrates to indicate when a direction must be changed. Similarly, another embedded IT application is the GUIDE-Me AIS prototype [59], which mounts small displays in medication containers to indicate which pill must be taken, in what doses, at what time, addressing in this way the determinant of adherence to a treatment. The Cook's Collage [122] also follows this line by embedding a situated display and a recording camera in the kitchen furniture in order to first record pictures of the steps necessary to cook a meal and subsequently display these pictures to aid the person remember the process, addressing then 
the determinants of psychological factors and housing and daily living. The BioAid iPhone hearing aid app (http://bioaid.org.uk/) is another assistive example, turning an iOS device into a hearing aid by processing sound from the microphone and then delivering it over headphones in real time, thereby compensating reduced hearing abilities in older adults and addressing biology and genetics factors.

IT systems can also act as facilitators of daily life activities, compensating for lack of mobility and strength. This is the case of the Gesture Pendant [122], a wearable necklace that interprets hand gestures in order to perform home related tasks like opening a door, dim the lights, or close the blinds, addressing in this way the determinant of housing and daily living. Similarly, compensation through facilitation can also be achieved by designing user interfaces with a focus on specific limitations, like visual impairments (i.e., biology and genetics factors), which are not limited to older adults only, but can also benefit younger users who are also visually impaired in some way. For example, BigLauncher (http://biglauncher.com/) provides an Android launcher application (i.e., a UI theme) that uses fonts, icons and colors suitable for users with limited vision. Similarly, the No-LookNotes is "an eyes-free system that uses multi-touch input and audio output" [17] to guide a blind or visually impaired person while writing on a smartphone. Other auditory interfaces are the WebAnywhere browser [16, which facilitates internet navigation using the voice and provides an audio output of the content in websites; and the PENPAL [174], which is an electronic pen that scans and reads out loud any text document. In general, most of the IT applications for accessibility (e.g., screen readers like JAWS - http://wWw.freedomscientific. com/products/fs/jaws-product-page.asp) are suitable to compensate visual impairments that come with age.

In the same way that BigLauncher compensates visual impairments with a carefully designed user interface, the IDBlue special pen [79] compensates the lack of skills in using technology by offering a more natural interface to interact with a digital agenda system. Lack of skills with technology often leads to frustration and a decrease in selfesteem, which is part of the psychological factors determinant. The 
digital agenda organizes daily activities and medical visits. The pen can read RFID tags that are attached to images on a special board. Like a remote control, each image represents a functionality of the agenda that runs on a PC. When the user taps an image with the pen, the associated tag is read and transmitted via Bluetooth to the computer, which interprets and executes the actions on the system. The digital agenda in itself is also an example of an assistive application for compensating declining memory.

A second way in which IT compensates age-related cognitive decline is via alerting applications, the most typical example being medication intake reminder systems that alert the person when it is time to take a medicine, addressing the determinant of adherence to a treatment. The e-Pill medication dispenser family (http:// www.epill.com/), EMMA (http://www.inrangesystems.com/) and RMAIS (RFID-based Medication Adherence Intelligence System) 113 are some examples of embedded reminders in medication dispensers (i.e., custom- made devices that organize and facilitate the retrieval of pills). Alerts can be auditive, visual or even phone calls that will only stop once the patient takes the pills from the dispenser. If missed, e-Pill dispensers will also send SMS or email alerts to caregivers. We mention only three in this paragraph, yet alternatives abound in the market and in literature [113. Other examples of medication intake alerting applications are implemented as smartphone applications, which is the case of UbiMeds [154], Wedjat [178], AIS REMIND-Me [59] and the Medication Compliance System [135].

Another interesting usage of alerting systems is for compensating visual impairments to address the determinant of mobility and transportation through the use of ultrasound detectors (i.e., like the sonar of submarines) integrated with walking canes to detect objects that are further away from the original cane length. Once the sonar detects a potential obstacle, the cane would start to vibrate to alert the person about the obstacle. Examples of this are the Ultracane (http:// www.ultracane.com/), the K-Sonar (http://www.batforblind.co. $\mathrm{nz} /$ ) and the Miniguide (http://www.gdp-research.com.au/minig_ 1.htm). 
A third way of IT for compensation is the use of monitoring applications, commonly part of alerting systems, that complement the task of compensating cognitive decline for addressing adherence to a treatment. As an example, radio frequency identification (RFID) technology has been used to add monitoring in medication dispensers [113] 76$]$. RFID tags are attached to medication boxes. The medication dispenser uses an RFID reader to scan the medication box and read information about the treatment and the doses stored in the RFID tags. This information is compared with the measures of a scale that weighs the box after the pill is taken, to monitor how well the treatment is followed and inform the user. CARE-Me [59] is also a monitoring application for compensating cognitive decline and improving medication compliance. It uses a positive feedback metaphor in a digital photoframe to inform about compliance and make the patient aware of the progress. The metaphor is a tree populated with parakeets. Each parakeet represents a week of the treatment and grows in size after every day in which the dose of the medicine was correctly taken. At the end of the week, the parakeet flies away and a new one appears [59. This is one of the very few systems that integrates a persuasion technique to motivate the person in achieving a goal.

The Fujitsu smart stick (http://www.bbc.co.uk/news/ technology-21620624) and the alerting mobile application proposed by Qudah et al. [135] can be also listed as monitoring applications. The first uses $3 \mathrm{G}$ or Wi-Fi connectivity to send positioning data back to a host computer, where caregivers or relatives can monitor the person's position, along with other vital signals like the hearth rate, addressing mainly that person mobility and transportation. The second uses data-mining algorithms and bio sensors for analyzing patterns of medication intake in relation with vital signals (e.g., hearth rate), with the hope of better understanding medication effects, addressing then adherence to a treatment.

One last monitoring application that belongs to the domain of compensation is the memory aid Show me the Video proposed by the HERMES project [24]. This application records a video stream of the older adult's house events, and then replays them in a tabletop device to help 
the beneficiary to remember the event, addressing psychological factors and compensating for age-related reduced memory.

The fourth way of IT for compensation is the use of serious games to compensate for reduced memory through the means of an entertaining game. In this line, MoviPill [4] addresses the determinant of adherence to a treatment, improving medication compliance by persuading patients with a mobile phone game that fosters social competition. Each time the patient takes the medication, a score is calculated based on how close to the prescription time it was taken. At the end of each week, the game highlights the week's winner to all players and resets the game for the following week. A second Serious game that also help to compensate age-related reduced memory (i.e., psychological factors) is the HERMES Maze [24], which is deployed in a tabletop device and challenges players with a maze that has an appointment sheet as the reaching point. The player has two starting points, one with "appointment clues" (e.g., medical visit) and the other with "time clues" (e.g., 11 a.m.). By playing the game, an older adult with memory related problems can be aided in the recall of real life appointments with doctors or medication intake schedules. In terms of evaluation, only De Oliveira et al. [43] include a study where the effectiveness of social competition was compared to the use of reminders, finding that social competition augmented compliance.

Finally, the field of Robotics has also contributed with social applications in the form of robots that provide companionship and sense of social connectedness to compensate loneliness and thereby address psychological factors. Generally, they are used by seniors who are under psychological therapy for dementia or depression. Two examples of this type of robots are the Huggable [162] and Paro [176]. Both Paro and the Huggable are therapeutic robotic companions with sensitive skins that react to touch to trigger some type of response of the robot. The Huggable serves also as a communication and monitoring medium, collecting information in the form of video and audio, which is later sent to a health professional, who can in turn monitor the progress of the patient and communicate directly with him if there is a need. A field trial of Paro shows both a psychological improvement and a physiolog- 
ical indication of stress reduction (via urinary tests) after interacting with the robot for a while [176].

\subsection{Discussion}

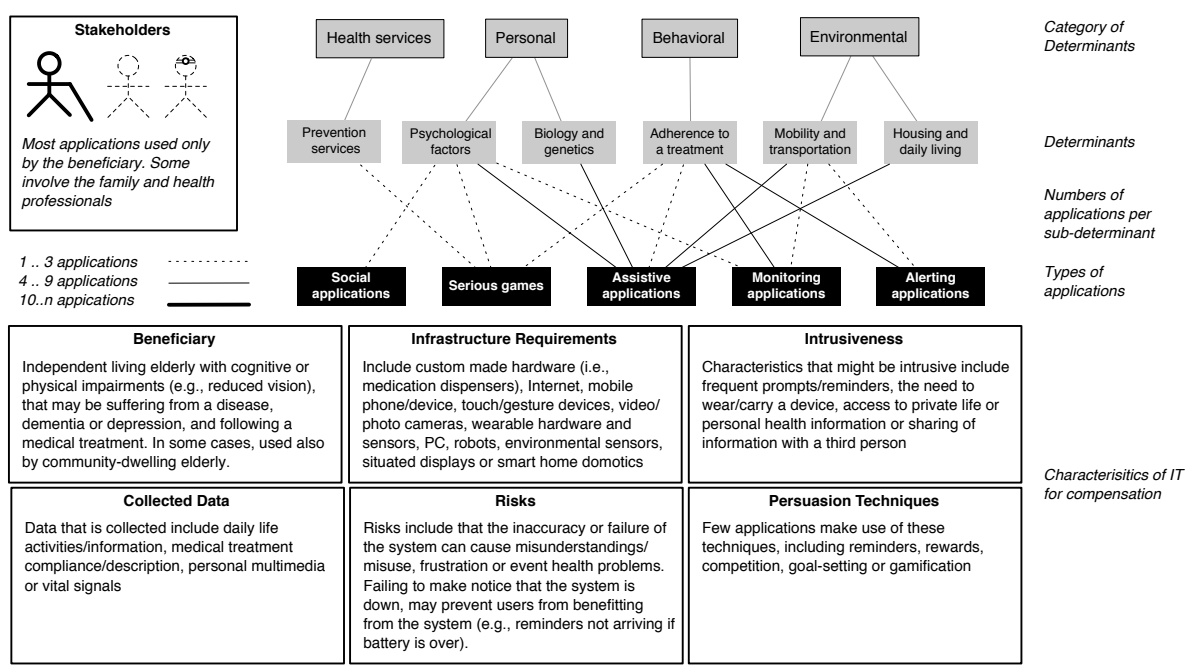

Figure 6.1: Typical characteristics of IT solutions for Compensation

Compensation applications are mostly used by older adults independently, mostly because they are oriented to older adults that have either cognitive or physical impairments that need to be compensated (e.g., lack of memory, visual limitations, hands tremor, etc.). Compensating a cognitive and some physical decline (e.g., loss of sight or hearing) often requires to work on building physical artifacts or infrastructure (e.g., walking canes, motorized wheelchairs, hearing aid devices, ramps etc.). This is what is usually referred to as assistive technology and we have decided to draw a line on what we consider IT by including only applications that process and store information that people can consume or interact with. It is common that IT applications for compensation require then some form of custom-made hardware (e.g., medication dispensers). Mobile devices and wearable sensors, combined with home automation equipment, are other typi- 
cal infrastructure requirements. Family and doctors are involved when monitoring applications are used to track medication compliance, allowing them to know when a person has not taken the medicine. In general, alerting applications for compensations are oriented to selfsufficient people, able to follow instructions. Monitoring applications for compensation aim at extending assistance in the form of additional control. Not including common assistive technology applications, IT for compensation mostly contributes to compensating cognitive decline related impairments.

Frequent reminders and access to personal health information (e.g., medication compliance, daily life activities and vital signals) are common elements of these applications that could potentially be perceived as intrusive, raising privacy concerns. Constantly wearing or carrying devices or sensors (e.g., the gesture's pendant) can be perceived as physically obstrusive [115], which is why this aspect needs to be designed carefully to render their benefits clearly in order to reduce this perception. When the benefit of technology is noticed clearly and they are seen as relevant, people are willing to make concessions about their privacy [151]. More importantly, since people will rely on these applications for guidance, there is a risk of producing more harm than good if the guidance is not correct or appears in the wrong moment. Persuasion techniques (e.g., goal-setting, rewards, social competition) are used in this domain, mainly for addressing medication compliance by keeping people motivated to follow their treatments. This seems to be a promising direction that has not been thoroughly explored yet.

As final note, there is clear tendency toward more integration between physical artifacts and information and communication technologies (like in the case of the augmented canes). More and more, assistive hardware is merging with information and communication technologies, resulting in an emerging field of opportunities for new and innovative assistive services.

Figure 6.1 visually summarizes this discussion, showing the different types of applications, Active Ageing determinants they affect and their aggregated characteristics according to our evaluation framework. 


\section{7}

\section{IT for Care Support}

IT for Care comes into place when a problem can no longer be prevented nor compensated, and assistance is needed, either to facilitate recovery from an incident or to reduce the impact of a chronic condition.

\subsection{Applications for Care}

The first approach to care support is the use of alerting applications aimed at taking care of older adults by alerting someone about the occurrence of an event, with the goal of triggering response when falls, missed or due medications, lack of activity and other adverse situations put older adults at risk.

The major part of these applications are for detecting and alerting about falls. Thanks to these alerts, caregivers can immediately react and avoid or at least reduce the risk of more serious injuries. Most of these systems rely on wearable sensors that leverage on the use of tri-axial accelerometers to monitor body motion and detect falls [21, 156, 170]. In addition to accelerometers, Doukas and Maglogiannis [48] collect and monitor sound data, combining it with movement data in order to detect falls of patients. Chen and Lin [32] introduce an 
RFID- based gait monitoring system to assist caregivers detect stumbles and falls. Tests in laboratory were successfully performed to check the effectiveness of the fall detection system. Of these evaluations, only Doukas and Maglogiannis [48] performed a pilot study with real people, involving 5 older adults. The results of this study showed that the mobile device to detect the falls was effective in doing so, but the especial vest designed to carry the device was uncomfortable.

Next to wearable sensors, mobile devices and applications have been explored and tested to alert about falls [28, 51, 84]. These applications process the data collected by the phone's accelerometer, and when a fall is detected, send an alerting message first to the user himself, and, if the user does not reply, to a list of emergency contacts.

Another approach to alert about falls is supported by cameras. In that case, the images captured by a set of cameras installed in a given environment are continuously processed and monitored in real time to detect falls, and alert caregivers using a personal computer or a dial center in case of a fall emergency. For instance, Shieh and Huang [153] propose a "human-shape-based falling detection algorithm". Doukas and Maglogiannis [49] and $\mathrm{Yu}$ et al. [189] leverage on the combination of audio and video information, known as multimodal processing, using a speech recognition system to double check a possible fall by also analyzing the extracted voice. Fernández-Caballero et al. [54] "mix accelerometer-based fall detection and computer-vision-based (visible and infrared) fall detection".

Environmental sensors are also an option to detect and alert caregivers about detected falls. Alwan et al. [3] introduce a floor vibration based fall detector combined with "battery-powered pre-processing electronics to evaluate the floor's vibration patterns and generate a binary fall signal". Whenever a fall is detected a wireless transmitter sends the alert to a communication gateway, that in turn forwards the alert to caregivers. Alertings systems for fall detection and response can enable Active Ageing by supporting and improving care and prevention services.

As previously noted, alerting applications are also applied to warn caregivers about problems of adherence to a treatment. For instance, 
UbiMed [154] is a mobile application that offers automated scheduling, reminders and tracking of prescription drugs intake, including proactive alerts sent to physicians and relatives when the patient fails to adhere to the prescription regime. The medication compliance system [135] is another mobile application that integrates a medication compliance system with the use of biosensors (e.g., electrocardiogram) to "monitor and provide personalized feedback to cardiac patients and health professionals". These two applications also aim at compensating memory loss and improving adherence level to a treatment as described in Section 6 ,

In addition to mobile applications, some contributions integrate alerts to caregivers in medication dispensers like e-Pill (http:// www.epill.com/), EMMA (http://www.inrangesystems.com/) and RMAIS [113]), with the goal of assisting people in managing their complex medication regimen autonomously at home, without the active support of a caregiver but still involving the latter in monitoring compliance.

The second most common approach to care in our review uses monitoring applications to track the health, daily life activities, and dangerous situations (e.g., fire, unknown people breaking into the house, or older adults lack of activity) of older adults, aiming at providing better and faster care when necessary, improving in this way both health care and prevention services determinants. Examples of these applications, use wearable sensors to monitor vital signals and body motion, share such information with caregivers who evaluate their behavior and, intervene when there is a problem (e.g., low vital signals, high blood sugar, low pressure) [26, 103, 114]. Monitoring application also leverage on the use of wearable sensors to collect data about seniors' daily life activities to detect low levels of activity, e.g., a symptom of depression or a coming disease, and inform health professionals about this [38, 93, 188. Some of these applications are also used as alerting applications that remind the older adult about upcoming events like a visit to the doctor, the time for taking a medicine or the time to buy groceries [188, to encourage them to be more active. Some alerting applications that are used for improving adherence to a treatment 
are also bundled with monitoring applications that collect information about medication compliance and sends it back to doctors or the family for following up [113, 135].

More focused on health information, DigiSwitch [27] captures images from daily activities of older adults, allowing them to view this "information as it is collected and temporarily cease transmission of data for privacy reasons". Holzinger et al. [77] collect vital signal and body position data to detect abnormalities (e.g., faints, low or high heart rate) and call an assistance center (which makes it also an alerting application). Cameras have also been used for the monitoring purpose, Nasution and Emmanuel [124] leverage on posture- based events recorded by cameras to identify possible intruders. Appiah et al. 6] and Shankar et al. [151] adopt cameras aiming at monitoring daily life activities and alerting caregivers in case of unexpected behaviors (e.g., the person under care did not wake up or has spent many hours on the bed, undesired people inside the house). Monitoring applications can also be used to help health professionals in providing assistance, like the case of Lifeline [64, a monitoring system used by doctors to follow patients with cognitive disabilities while they try to accomplish a task and conveniently help them if they detect that they are lost, having a positive influence in the feeling of safety of patients, part of the psychological factors determinant.

Another approach to care comes in the form of serious games and exergames. Both have shown to be effective for improving older adults care by the means of, for instance, rehabilitation sessions in virtual reality environments. This approach presented good results in motivating and improving physical conditions of older adults recovering from hip fractures [62. Moreover, Nintendo Wii Fit has been used to improve older adult's balance during stroke rehabilitation care sessions [166]. Both applications were tested with real users. The first approach, was tested with 66 participants, $98 \%$ of which felt less fear of falling after the physical intervention period. The second test was focused on feasibility, showing positive results in a clinical setting, where the only participant of the study improved balance and self-confidence. Sugarman et al. [166] state, however, that "further studies need to 
be done in order to assess the social validity and effectiveness of the use of the Wii and similar gaming systems as a treatment modality". Improvements in reducing the fear of falling have a positive impact on the psychological factors determinant. The use of these games as part of rehabilitation therapies can improve the care services determinant.

Closely related to games, training applications are also used for care. Deployed on tabletop devices, some training applications have been used during upper extremity motor rehabilitation care sessions in order to improve motor control [5]. This approach was in the process of being installed in the rehabilitation hospital. The initial responses the authors received from the therapists were positive, which indicates that these application can potentially improve care services by facilitating the delivery of training from real therapists.

Finally, only one IT for care contribution in our review falls well under the category of social applications, improving the social support determinant through a cognitive training platform where caregivers can assist patients with cognitive impairment in cognitive tasks that are part of training program [116]. Although this application can be also classified as a training application that addresses psychological factors, the focus of the contribution is set on the platform to involves the family network in assisting the cognitive training from remote, putting the social aspect upfront.

\subsection{Discussion}

Most of the care applications focus on assisting independently living older adults, in order to prolong their independence and consequently postpone their entrance in a nursing home. Care applications are characterized by the involvement (in the use of the system) of all three stakeholders of our evaluation framework: beneficiaries, health professional and the family. The goal is often to support remote healthcare monitoring of older adult's daily activities, health status, and adherence to treatments.

Among the applications, alerting applications (mainly for fall detection ) and daily monitoring solutions are the most widely researched. 


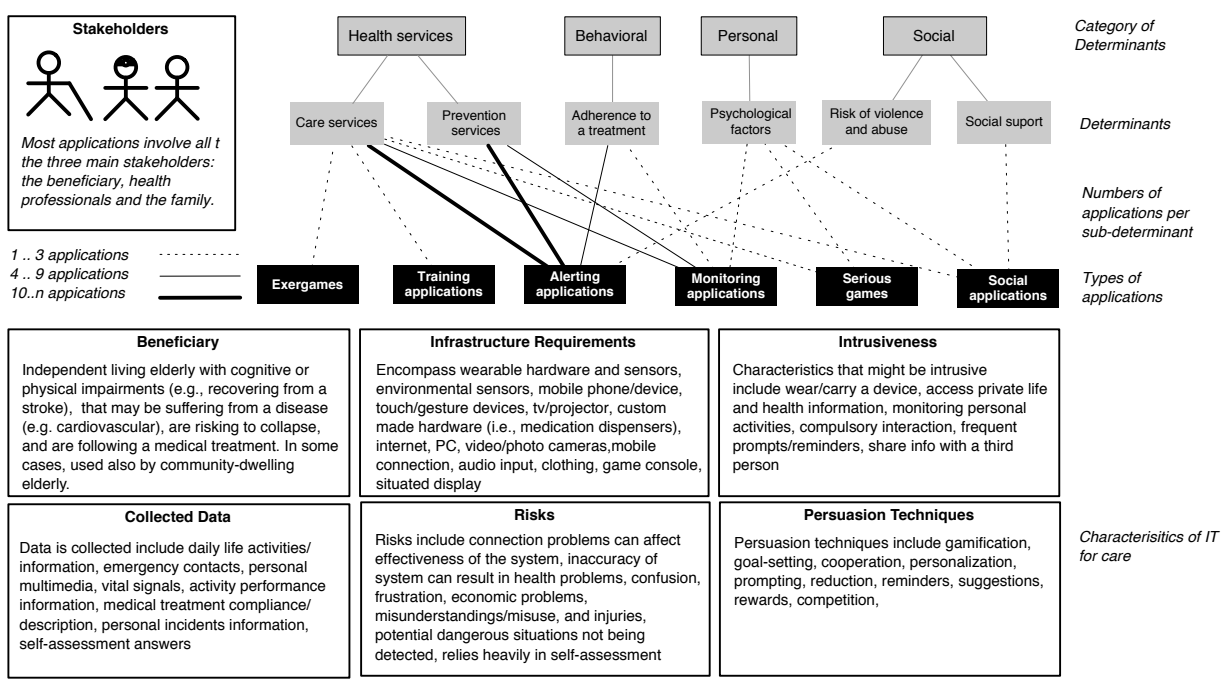

Figure 7.1: Typical characteristics of IT solutions for Care

In the former, the older adult needs to carry or wear a special device (e.g., mobile phone, body sensors) or be surrounded by sensors, cameras, or microphones to monitor his environment. Such approaches make the daily life of older adults safer in the sense they can receive fast assistance when risky situations are detected (e.g., falls, unconsciousness, potential symptoms of a disease). Proper monitoring and alerting systems can lead to fast diagnosis and reaction from caregivers in case of emergencies. In addition, they increase the sense of security and diminish the fear of falling [62, 166, affecting positively not only the wellness of the person being monitored, but also their physiological and emotional conditions.

Privacy issues are critical in these applications since sensible data needs to be collected, stored and analyzed. Due to the risky nature of the situations that care applications are designed to control, accuracy is an important aspect. Lack of accuracy is hence among the most important risks aspects on care applications. Moreover, depending on the approach, the person who is being monitored can feel too much control over him/her in addition to privacy concerns, which may cause 
some discomfort. Wearing a body sensor or carrying a smartphone all the time increases the intrusiveness of such services.

Exergames, serious games, and training applications have also been explored and tested as means to keep older people mentally and physically active, although only with small user samples and during short periods of time [5, 62, 166]. In such preliminary studies, researchers noticed that these games decreased participants' fear of falling, and also improved their balance.

Care and prevention services, along with adherence to a treatment are the determinants most addressed by care applications. In contrast, a few of the care applications we have reviewed have an impact on other determinants including psychological factors, social support and risk of violence and abuse. When addressing psychological factors, the goal is either on facilitating family involvement on cognitive training [116] (which in turns increases social support) or on facilitating the task of remotely following and assisting daily life activities [64] of patients with cognitive disabilities. More evaluation, however, is needed to establish the effectiveness of these applications. As for the risk of violence and abuse determinant, the only solution in our review that can have an impact on this leverage on a mixed monitoring and alerting approach that uses a surveillance system that controls house entrances and alerts caregivers and family members in case of undesired visitors. In this context, an evaluation has found these type of systems are only accepted when their usefulness is clear. Moreover, spatial privacy (where the camera is placed) is less important than activity sensitivity (what is the activity that is being monitored). A camera in the door to provide security is then much more accepted than a one inside the house due to different nature of these different spaces [151].

An important note on applications for care is that they often fall in the borderline between care and prevention (especially, monitoring applications). When the main goal is to facilitate the provision of care in case of emergencies rather than preventing a particular situation from happening, we have categorized the system as a care application. Borderline issues also appear often with compensation, because the provision of care in itself can be seen as a way of compensating for a 
lack. However, we have generally applied the rule of classifying a system as compensation when the system does not involve a third person to provide some form of care.

Figure 7.1 presents this summary visually, showing the connections between Active Ageing determinants and types of applications with their aggregated characteristics according to our evaluation framework. 


\section{IT for Enhancement}

Enhancement is about enriching the life of people by opening new opportunities for participation, health and security. The last group of contributions we describe in this paper fall under this category.

\subsection{Applications for Enhancement}

The first and foremost way in which IT enriches opportunities of life it is through social applications. Some of these adopt a holistic approach, trying to enhance opportunities in many aspects of people's social life. Life2.0 [85] is an example of this, envisioning a web-based

platform targeted at senior citizens and their local communities, where they can easily see who is around, what is happening and communicate with others in the community, improving their social support. The platform addresses also the employment determinant by allowing older adults to explore who can help with a task and also offer help or other services on their own. The iNeighbour TV (http: //socialitv.web.ua.pt/index.php/projects/ineighbourtv/) also addresses both these determinants by offering similar functionalities but with a user interface more familiar to seniors: their TV 
sets. NextDoor (https://demo.nextdoor.com/) and HomeElephant (http://www.homeelephant.com/) are other similar community oriented social networking platforms (in this case focused on neighbourhoods), which are not specifically tailored for seniors but that can fit their needs and increase their social support. Not focused on local communities but also aiming at a broad range of social needs, the Silverline project (http://silverline.mobi/) is developing a family of smartphone applications tailored for seniors like Discover, which will allow them to share their daily activities on the go; and Inspire, which delivers inspirational stories in text, picture and video formats on a daily basis with the goal of enhancing their subjective wellbeing.

Other social applications focused more strictly on enhancing socialization, allowing older adults to share something of their interest (and hopefully of interest to others too), interact and communicate with others. NetCarity [99] addresses social support by facilitating socialization with family and community through tabletop applications such as the Social Window and the Public Square. In the first, each member of the family is represented by a house, forming a virtual neighbourhood where, by tapping on a house, the senior can get status information and options of communication with that person. In the second, the user interface emulates the central square of a community, where people would physically meet, including news boards and containers for sharing digital media by dragging and dropping local media on the square. Other applications aim to enable novel ways of interacting for people who are away of each other. StoryVisit [136, for example, extends the experience of video-conferencing by allowing adults to read and tell a story book to younger children using a web application that synchronizes the story at both ends of the communication, displaying the text of the story on the screen of the reader, and text with pictures (like a real book) on the screen of the child listener. This allows older adults to stay connected with their family in a funny way, improving social support and communication access. Similar systems that are commercially available are Playtell (http://playtell.com/), Readeo (http://www.readeo.com/) and $A$ Story Before Bed (http://www.astorybeforebed.com/) Remote so- 
cial interaction for seniors has also been addressed through the means of simplifying traditional social networking services like facebook. FamilyRibbon (http://www.familyribbon.com) is an example, offering both tablet applications and web front ends to use a simplified user interface of facebook. Similarly, Phiriyapokanon [133] has proposed a redesign of facebook with an emphasis on metaphors that are common knowledge to seniors, like a newspaper deployed on an iPad

Face-to-face socialization can also be improved with IT to address social support. SharePic [7] is a tabletop application that allows multiple users to share pictures and collaborate in their management or in the creation of other picture-based resources like postcards and collages, while they are together. Similarly, The Timecard [129] and the Shoebox [10] can enhance face-to-face interactions by triggering conversation when people are together, exploring old memories, which in turn can positively influence psychological factors like their self-esteem or coping styles (i.e., the conscious effort placed on solving difficult personal and interpersonal problems). These two applications allow older adults and their families to organize and explore life memories using a situated display embedded in artifacts that imitate familiar physical objects like the shoe boxes people used to put pictures in. The Timecard was particularly seen by users as a way to cope with loss of family members [129. In the same line, Reminiscens [131] is a tablet application that stimulates storytelling of personal memories by displaying contextual multimedia around life stories. The goal is to motivate intergenerational face-to-face interaction to address social support and stimulate reminiscence to address psychological factors. The same goal is pursued by CIRCA [65], but with the focus placed on supporting reminiscence therapies for dementia patients. Although not for face-to-face interactions, other applications that also support reminiscence to address psychological factors and allow older adults to share their stories to address social support are the Project Greenwich 169 and the Book of Life by the european project SOCIABLE (http://www.cognitivetraining.eu/). The first offer a website for older adults to share their life stories while the second one is a tabletop application that emulates a book where each chapter corresponds to 
a different stage of life (e.g. infancy, adolescence, and adulthood). A final example worth of mention is MEMENTO [180, a system based on a physical interface, the ANOTO pen and paper, to allow seniors to write their stories in a physical paper while their writings are automatically digitalized. The final story is both digital and physical, enabling sharing via email or in face-to-face interactions.

The knowledge of older adults can be important also for collecting and preserving the collective memory of a community. For example, Memoro (http://www.memoro.org/) is a mobile application to collect videos of older adults telling their stories and advises, automatically sharing the video on a public web site with the purpose of preserving their knowledge and wisdom, positively affecting their psychological factors. Also the PACE telementoring platform [14] leverages on the knowledge of seniors to help young people in learning languages or any other skill during a video conference call, which increases older adults social support. Similarly, wisdom/knowledge sharing websites like the Elders Wisdom Circle (http://www.elderwisdomcircle.org/) and The Amazings (http://www.theamazings.com/) open new opportunities of employment to seniors that want to offer their counselling to others that might need it. In The Amazing, the sharing takes the form of online courses that cover a wide range of topics including, among many others, knitting, water color painting and gardening. The TimeCapsule 104 is a final example for this paragraph, addressing social support by offering a social networking service that allows seniors to digitalize old pictures, add location information and write stories about them so other people can later see and comment on these pictures when they pass by the place where the pictures were taken using a mobile application.

Also for enhancing the social support determinant, some social applications seek to improve participation of older adults in local community events. The Mirror Motive [151] aims to achieve this by detecting when the old person is near the mirror and then displaying general information about the local community, including invitations to social events that will take place nearby. A more subtle way of participation is by consuming information shared by friends and family, increasing 
their awareness of their lives. ePortrait [39] connects social networking services to a photoframe situated in the house of the old person. Pictures posted by the family in a closed group of facebook are automatically downloaded to the photoframe. A similar system is proposed by Biemans and Dijk [15], which uses SIM-based photoframes where family and friends can send MMSs with pictures and text. Using a tablet instead of a photoframe, Rodríguez et al. [138] propose an "electronic newspaper through which older adults and their families share information, personal reminiscences and stories", interacting also in real time through a turn-by-turn memory cards game.

A second general way of enhancing life is by improving and increasing the means of communication, addressing the determinant of communication access. Communication applications fulfil this role, with some focused solely on improving, facilitating or increasing access to communication mediums. What's Up [46] is an example of this, facilitating intergenerational communication by providing a communication platform and a tablet application specifically designed for older adults to receive messages from their younger relatives and friends, who in turn use their smartphones. The main goal of What's Up is simplicity, giving older adults a tool in which they do not need to do anything while messages will just arrive and appear on their tablets. An evaluation of What's Up based on think aloud protocols and questionnaires revealed that the older the user, the simpler the UI that is preferred, putting simplicity as one of the most important features. Other systems similar to What's Up with extended capabilities and commercially available are VideoCare (http://www.videocare.com/) and ConnectMyFolks (http://www. connectmyfolks.com). In the same line, senior oriented smartphones and tablets are comercially available, most offering a simplified UI of smart mobile systems, oriented to users that engage with a touchscreen or a smartphone for the first time in their lives. Examples include the Fujitsu Stylistic S01 (http://www.fmworld. net/product/phone/global/convention/mwc2013/mwc01), Emporia (http://www.emporia.eu/en/home) and Doro phones and tablets (http://www.doro.com). 
Other applications address the determinant communication access with tools to support person-to-place communication, which provides a communication link between the family that is constantly on the move and the older adult who is staying at home. The Epigraph [101] and the HomeNote [150] are two noticeable examples, by which people can send messages directly to a place (e.g. home) rather than a person. The first uses an special touchscreen display where older adults can select from a list of channels, each corresponding to one member of the family who can update the channel via email or SMS. The HomeNote is very similar, with the addition that it supports also local scribbling by using a stylus to write over the device, to leave notes that are meant to be read by anyone at home. Similarly, the Message Center [186] relies on a piece of paper for seniors to write messages which are automatically scanned by a special device and sent either via email, SMS or fax to a mobile phone, a PDA or a fax machine. The same device can also receive messages and print them. Other systems in this category are Wayve [102, Collage [175] and On Message @ Home [132]

Enhancement also addresses the determinant of social support with monitoring applications oriented to increase participation in the lives of family and friends by increasing awareness of their whereabouts. The Ambient Plant [151] is exemplary of this, with a system composed by two flower pots at different houses that detect when a person is nearby and and notifies about this to the remote side, where lights on the pot will be turn on to inform the person on that side about the presence in the other end. The goal of this system is to increase feelings of social connectedness by letting the older adults know when the family is at home. This simple awareness about family whereabouts has been pointed out as a way of supporting the peace of mind for extended family members (i.e., those living away) [139]. The Home Awareness prototype [107] has the same goal, only in this case the focus is set on a remote place, collecting information of that place's environment and reproducing it at local side. A special home device is installed at the receiving home to reproduce the remote environment's light, temperature (using a controlled fan) and sound (using skype), which, according to a field trial, can be translated in people having a picture of 
the remote place constantly in their heads, triggering practical concerns (e.g., it is time to mow the lawn again) and giving them a feeling of satisfaction and connection. Another example in this line is the Digital Family Portrait [123] that uses a situated display to show daily life events of an elder in the form of icons around a portrait located at the house of the family. The Whereabouts Clock [149] does something similar, but displaying information about the family at the elder house. Using information of the GSM cell ids in family members cellphones, the system displays location information of each of them in a situated display that has the form of a clock with pictures of the family members moving around. Sellen et al. [149] evaluated the Whereabouts Clock and found that visual representations of family whereabouts increased the sense of community. A more recent commercial product in this line is Lively (http://www .mylively.com), which enables automatic activitysharing between family members using special low cost sensors that are attached to everyday home objects like the fridge or medication containers. These sensors automatically sense when these objects are moved, and depending on those movements, infer what the activity is for later sharing with the family a summary of daily life patterns.

Exergames and serious games that are played with others to enhance socialization can also serve to improve social support. There are basically two types of serious games in this domain: those that aim to enhance social interactions and exergames which serious purpose is to enrich physical activities of older adults. In the space of social interactions, Mahmud et al. [109] propose an inter-generational game, deployed in a tabletop device, where older adults and their grandchildren compete to find a princess in a maze. In the same line, Age Invaders [90] is an augmented reality game deployed on a special display integrated with the floor of the house. On top of it, older adults and their grandchildren play in teams following footprints and other that appear on the floor. Age Invaders is also an example of an exergame that helps to improve physical fitness by enriching physical activities of older adults.

Finally, one last way for enabling Active Ageing through enhancement is using eLearning applications to address education and em- 
ployment determinants by allowing older adults to gain knowledge and skills that can help them to improve their participation in society. RefocusLab (http://www.liuc.it/cmgenerale/centri/cetic/refocus/ default.htm) and SeniorLearning (http://www.seniorlearning.eu) are two platforms of eLearning oriented to older adults. Both are based on the open source eLearning platform Moodle and are proposed by European Projects with the goal of training older adults in information communication technology (ICT).

\subsection{Discussion}

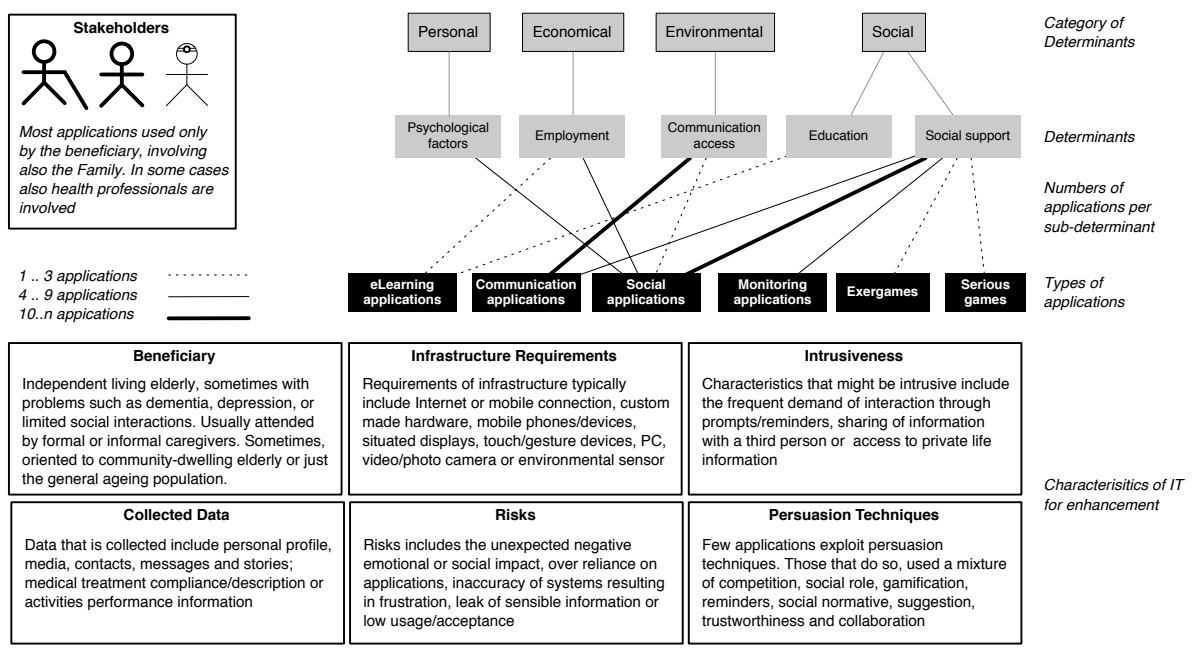

Figure 8.1: Typical characteristics of IT solutions for Enhancement

Enhancement applications improve or open new opportunities for socialization, communication and both contribution to and participation in society. In particular, IT has greatly contributed to enrich opportunities of the ageing population in terms of social support and communication access, connecting them better to family, community and professional caregivers and benefiting almost in equal measure independent living, community-dwelling and older adults living under formal care in assisted living facilities. Our review presents a preva- 
lence of social and communication applications above the other types of applications. Interestingly, also monitoring applications have an impact on social support by facilitating constant awareness about family and friends' whereabouts. While privacy is not at concern if the applications are perceived as useful, there is a need to support ON, OFF and PAUSE for monitoring [151.

Most of the contributions we have reviewed involve the end beneficiary and the family. To a lesser extend, health professionals are sometimes involved as well. Usually, they demand constant or too frequent interaction through prompts or reminders, which is an aspect that needs to be designed with care not to become intrusive. In the same measure, data collected by enhancement applications very often include personal information and social contacts, which is also an aspect to design carefully not to become a barrier for adoption.

Because of the prevalence of social and communication applications, the most common determinants that are addressed by enhancement applications are communication access and social support. Since many of these applications have an strong emotional impact, psychological factors can also be influenced by enhancement. The risk, however, is that these system could also have unexpected negative effects on people's emotions. For example, when an older adult is put in contact with their personal life and memories, we have observed in our practice that some perceive this as a reminder of their age, while at the same time others find it rewarding and joyful. The emotional impact of the application is thereby and important variable to control when building enhancement systems.

On the other hand, few contributions we have analyzed explored the dimension of keeping older adults in their work to address the employment determinant. These contributions are mainly focused in allowing older adults to share their knowledge, experience or wisdom for the benefit of younger people or peers. Building systems that can help seniors to keep contributing to society, is an area that still holds many opportunities for innovation. Crowdsourcing could be an area to explore for this. Mutual help systems also hold some potential while raising some concerns about who administer the offering of help to 
assure that the seniors are not abused [85. There is also much to do yet in the space of education, to keep seniors active in learning new skills that can open opportunities for employment or simply interaction for them.

Another interesting thing to notice is that very few of the enhancement applications exploited persuasion techniques in order to increase social interactions and communication. This means that there is an open space for exploration of persuasive technologies that are specifically designed to motivate socialization.

One aspect that is emphasized by most enhancement applications is simplicity. This emphasis might explain why most applications for enhancement rely on touch or gesture devices, like tablets and smartphones, as means of interaction with the older adult, showing a clear trend towards natural or direct manipulation interfaces, which are usually considered as easier for users that do not have much experience with technology. Also because of this emphasis on simplicity, many social applications operate with the intuition that current popular social networking services are too complex for older adults, considering that the features of social services should be described in no more than 6 sentences [133]. In contrast to this, statistics show that senior users of social media continue to increase year after year [192], with one third of the Internet users aged 65 or more using social networking sites. After age 75, however, the Internet use drops significantly. This is an indication that traditional communication and social applications, like email and standard social networking sites, are finding a role for active ageing.

In summary, enhancement applications, along with care, are the most rich in terms of diversity of features that are used by individual applications, informing about general aspects of life and mediating communication and interaction being the most common features. Much of the work on enhancement address the emotional dimension of increasing the feeling of connectedness by providing awareness about our family or friends whereabouts or enhancing the person's self-esteem by giving some purpose to his or her life. This makes it extremely difficult to evaluate what is the actual impact of these technologies on 
people's wellbeing, resulting on a lack of strong evaluations in the form of randomized controlled experiments.

Figure 8.1 represents this summary visually, illustrating the relationship between Active Ageing determinants and types of applications. 



\section{9}

\section{Limitations of this review and related work}

Just as ageing is a complex and varied phenomenon that cannot easily be constrained into a closed set of characteristics, so is the landscape of ITs for active ageing. Although much of this landscape has been described in this narrative review, there are also some limitations, which we discuss in this section along with related works that can help complement a more deep and complete exploration of the topic.

First, since we have used a corpus of research articles and other types of resources that we have collected over two years of our research and design work within the computer science discipline, an important limitation is that most of the literature we cite in the core IT sections comes from conference proceedings (36\%). Journal articles (19\%) and Books (4\%) are less referenced, although they do account for more than project/product websites (15\%) and technical reports (3\%). While we encourage readers to complement this review with a further exploration on Journals, it can be argued that this distribution is due to the characteristics of the fields we have investigated, which are more conference-oriented. The first conceptual sections, where most of the human movement sciences and policy making literature is cited, shows 
a different pattern, based mostly on Journal articles (68\%) and policy making reports (15\%).

A second important limitation has to do with the density of our review: in order to show as much detail as possible coupled with an analytical discourse of the connections between the solution space and the problem domain (Figure 4.1), we have chosen a narrative approach by which the sections that describe IT applications and services present readers with a descriptive information first, and a discussion later. Moreover, because the categories of our evaluation framework are not entirely orthogonal, many systems we described fit well into more than one type of application, affect more than one determinant and can fulfil more than one of the technology goals. For example, medication reminders are alerting systems that usually come with an important monitoring side that keeps the family on the loop about the adherence to a treatment of a person. At the same time, a medication reminder help to compensate for memory or attention problems, while it also facilitates the provision of care by family members. For the readers who are searching a quick way of navigating the list of IT applications and services we have analyzed, we have prepared and made publicly available a table version with all these contributions, categorized according to our evaluation framework and with an accompanying description of the key messages we have found in each 1 .

Other interesting frameworks to classify technologies for active ageing can be found in the Quality of life technology handbook [147] and the report on the state of technology in ageing services, prepared by Alwan et al. [4]. The latter provides a classification of technologies and applications/services for ageing, depending on the scenarios of usage of the technologies. Our classification takes inspiration from some elements of this review, putting its emphasis however on "life course" outcomes (prevention, compensation, care, enhancement), which can be facilitated and achieved with IT.

A third limitation we can mention is that ehealth systems might seem under represented because it is not included as a type of application. Most of these systems, however, are a combination of alerting,

\footnotetext{
${ }^{1}$ The public dataset is available at: http://bit.ly/itforactiveageing
} 
monitoring and assistive applications, which is why we decided not to use "ehealth" as a category in our framework. Additionally, we believe "ehealth" is so ample as a topic, that should be covered in detail within a review on its own. In this review, we have focused more strongly on personal devices, tools and software for active ageing and less on the medical side of the problem, where ehealth and telemedicine are more important.

Similarly, other important subjects of discussion that we have not covered in detail, but will be considered in the future, is the evaluation and impact of active ageing IT. Partly, this is a limitation of the domain: most articles we have reviewed lack a proper evaluation of the efficacy of these technologies in terms of acceptance and adoption of technology; attitudes towards technology in general; trust, training and instructional support, among many others issues. On the other hand, this limitation comes also from our own decision of keeping the evaluation framework simple and limited to a closed list of analysis dimensions (see section 44). We argue that the dimensions we have chosen are the most important influencers of how much acceptance, adoption and trust can these technologies achieve. We admit, however, that they are not the only ones. Future work will be focused on specifically discussing impact under these terms, but a good review on issues like technology acceptance, adoption and trust can be found in the work of Beach et al. [12]

Two other subjects we have covered scarcely in this review, but that we think might deserve a more focused attention in the future are technologies oriented to caregivers and technologies for the support of ADLs (activities of daily living - feeding, grooming, bathing, etc.) or IADLs (instrumental activities of daily living - managing finances, shopping, preparing meals, etc.). Most ITs oriented to caregivers are actually made to facilitate the provision of care to their loved ones in the realization of their ADLs and IADLs. Albeit being focused only in family caregiving for people with dementia, a good review on this topic is the work by Schulz and Martire [148].

Some discussion on the topics we have not covered in detail might be found in other reviews, reports and studies on ageing and technol- 
ogy; and many of them served as the starting point for this review. The motivation why we felt a new review was needed is that most of these works either focus primarily on technology or they put their emphasis on ageing in general, without trying to bring together the two perspectives to analyze which IT solutions may serve to alleviate which aspect of the ageing process. The goal of this review is therefore to fill this gap and to connect researchers and practitioners working in the field of IT with researchers and practitioners working on gerontology, health, psychology and policy making.

Moreover, other works that are related to this review and can help to complement it, can be divided into four major groups: a) Health, Psychology, Gerontology and Human Movement Sciences articles; b) Ethnographic studies; c) Policy-making reports; $d$ ) and HCI and technology oriented reviews;

Health, Psychology, Gerontology and Human Movement Sciences specifically focus on ageing problems and their solutions from a medical (non-IT) perspective. In some cases, they also specifically mention IT solutions, however typically focusing on specific aspects only, such as, "physical activity" [36, 63, 100, 119]. Most of the works we have used to support our conceptual discussion of ageing and active ageing (see section 2) fit this category and have been referenced in this part of the review. Less developed in our review, however, is the psychological perspective. For a complete review of ageing from this perspective, see the work by Schaie and Willis [144] or, more focused on behaviour, Baltes and Baltes [9]. Also interesting is the work by Scheibe and Carstensen [145], focused on emotional ageing.

Ethnographic studies describe specific aspects of the ageing process and the ageing population from a more cultural perspective, giving interesting insight on how older adults live the different changes that age might bring. Elena Portacolone [50] for example provides a complete analysis on how older adults face the challenges of keeping independence by living alone (in San Francisco). More focused on how technology has an impact in the lives of older adults, Karavidas et al. [86. presents a complete review of this topic. Other interesting works in this line include [125, 127, 137, 179]. For space reasons, we did not 
elaborate on this aspect in this review. However, these references may help the interested reader to further strengthen his/her understanding of how technology, in general, has an impact on people's daily live as they grow old.

The most representative examples of policy-making reports are the WHO policy framework for Active Ageing [182 and the report about the role of IT for Active Ageing services prepared by the IPTS (Institute for Prospective Technological Studies of the European Union) [111. These works provide an excellent understanding of the ageing process from a policy-making perspective, clarifying what are its determinants and what is needed to deal with the process from a societal perspective. Given their focus on policies and regulations, they however lack insight of how IT can help improve the Active Ageing process.

HCI and technology oriented reviews mostly focused on how to design technology (i.e., proposing guidelines), how it is later used or integrated in people's lives, and what can be learned for the betterment of design of future systems. Many reviews, for instance, focus on usability principles guiding the design of technology. Phiriyapokanon [133], provides a broad overview of principles to design IT for older adults, along with a summary of the typical challenges older adults may face when using technology. Another good set of principles and general theory about ageing and technology are the reports on accessibility and ICT by the The John Gill Technology Institute (http:// www.johngilltech.com/guidelines/) and the many guidelines that followed the enacted US-based legislation of the American Disabilities Act (http://www.ada.gov/). Fisk et al. [56] and Mace et al. [108] are two interesting and comprehensive books on this topic, among many other works that we have used to construct the summary we presented in section 3.2 [31, 40, 80, 130, 134, 159, 164].

Other related reviews more specifically address usability, focusing on a particular aspect or interface like input devices (e.g., pointing devices, keyboards, mice, joysticks, trackballs, etc.) [167] or multi-touch screens [106]. These reviews provide interesting summaries about what is considered good and bad when designing a system for an ageing 
population (e.g., touch/gesture devices are more suitable than keyboard and mouse). Bouma et al. [20] classify different applications for visual independence from a Gerontechnology perspective. The review by Xie [187] studies the interaction of older adults with technology in terms of attitudes, perception and usage. The reviews by Mynatt et al. [122] and by Kientz et al. 91] provide an overview of home-based applications for their "Aware Home", a three floors house designed for facilitating research on the topic of technology for independent living, while providing an authentic home environment. Breazeal [22] explores how social robots can be applied in healthcare. With our review we try to bring all these specific aspects under one common framework that allows one to easily switch between technologies (solutions) and ageing aspects (problems).

Finally, a topic that has seen a lot of research lately is that of serious games and their impact in the promotion of cognitive functions. For an extended review of this topic, see the following list of works that have come to our attention only after we have finished our review [11, 18, 19, 181, 191] 


\section{0}

\section{Summary and Outlook}

In this review, we reviewed the different interpretations of Active Ageing according to the existing literature and showed its evolution over time. We discussed how Information Technology (IT) can serve not only to mitigate some of the negative side effects of ageing (e.g., physical and cognitive decline) but also how it can serve to give raise to new opportunities (e.g., by enhancing capabilities). We proposed a conceptual framework that brings together the two different perspectives and correlates the determinants that affect quality of life during the ageing process with the type of support IT can provide to modulate these determinants. We used the framework to systematically review exemplary IT services and applications that explicitly provide support for Active Ageing, an exercise that allowed us both to appreciate the extraordinary value IT may bring to older adults and, at the same time, to identify a set of challenges and opportunities.

We summarize these latter as follows, grouped by the four gerontechnology goals that accompanied us throughout this review:

- Prevention. Modern, IT-assisted prevention aims to promote lifestyle changes early in the life of a person. This is particularly visible in training applications and in many of the serious 
games and exergames reviewed in the paper. The increasing inclusion of specifically targeted persuasion strategies, aiming to increase effectiveness, into games and applications is particularly noteworthy in this context. Although the application of games to enable active ageing - but also to brake social isolation - is just in its beginnings, the number of IT applications in the serious games and exergames categories is already considerable. We read as an indication that the transformation of older adults into active, "playful" older adults is already ongoing. The question is whether this trend can be sustained with the availability of novel technologies only or whether there is something else that needs to happen for seniors to become more playful. A better evaluation of this aspect is needed to understand both the dynamics and, possibly, how to improve technologies. Partly, this is part of our own future work, e.g., in the context of the $A c$ tiveLifestyle [155] and The Virtual SocialGym research project (http://socialgym.org/) which both aim to enable and motivate older adults to stay physically fit and heavily leverage on suitable persuasion strategies.

- Compensation. Most of the identified IT solutions for compensation are oriented toward compensating the symptoms of cognitive decline, such as the loss of memory. This result is somewhat physiologic, in that we focused on software solutions and commodity devices for personal use. Especially for compensation, we however note an increasing integration of custom hardware with dedicated software and services. On the one hand, hardware is more and more carefully crafted in the form of wearable devices and sensors that are more powerful, more precise and less invasive and that keep the level of additional stress low. On the other hand, we have seen that compensation applications are most effective if they are integrated into the living environment of older adults, which is designed with their limits and capabilities in mind but without overly bringing attention over the limitations. In this respect, we expect to see a better integration of applications, devices and domotics in the near future. If we widen our focus a bit, 
we can see a trend toward bionics and robotics for compensation, which will enhance the human body with artificial extensions and improvements. The challenge here is understanding how to bring together IT and these novel technologies.

- Care. From an economical perspective, economical restraints will force us to translational and clinical research towards personalized medicine (diagnostics and treatment), thereby steering efficient therapy for Active Ageing, e.g., with companion diagnostics and increasing cost effectiveness. This demands academy and industry to provide completely novel tools and possibilities for innovation and potential commercialization within life science in close collaboration between health care, academy, and industry, focusing on individual needs. IT has allowed tremendous improvements and spreading of promising telemedicine applications, but, despite the technical maturity, telemedicine services for Active Ageing are still limited and the market remains highly fragmented. Telemedicine is a tool that should be integrated as much as possible into the usual practice of future public healthcare, however, the integration of telemedicine service in healthcare systems is still an open challenge. Home (re)habilitation is becoming one of the most appealing applications of telemedicine. The increasing share of older adult's population and the related expected increase in health care costs, are a strong incentive to search for new ways to assist Active Ageing for individuals at home, e.g., via dedicated technologies. For instance, we have reviewed several care applications, where monitoring and alerting capabilities are increasingly used in a home or informal environment to enrich the quality of health services.

- Enhancement. An interesting aspect we have noticed throughout our review is that the merger of physical assistive technology with information and communication technologies does not only bring an increasingly wide range of innovative services to prevention, compensation and care, but it also connects people with older adults and keeps them engaged in community activ- 
ities. Social applications are spreading among older adults and increasingly connect them with friends and their family/community circles. There is also an emerging thread of emotions-oriented social applications, whose main purpose is to enhance people's subjective wellbeing. An aspect we have seen is not yet well developed, is education or work for older adults. We expect the advent of MOOCs (Massive Open Online Courses) [105] as well as the crowdsourcing of work (e.g., via crowdsourcing platforms specifically tailored to older adults) to play a major role in this respect in the near future. Our future work in this space is represented by the Reminiscens project [131, which brings together older adults as narrators and young volunteers as listeners in storytelling sessions where a tablet application is used to facilitate the preservation of their memories while stimulating interaction with contextual multimedia and questions.

One important limitation of most of the literature we have reviewed, in all four categories, is that much IT is being developed but there is a minimal amount of research and testing on the efficacy of these technologies. To what extent do they really accomplish the goals of prevention, care, compensation and enhancement is a topic that must be further explored in the future.

While in the beginning the focus was mostly concentrated on accessibility, today the landscape of IT for active ageing is much more varied, open and rich of opportunities. Much has been achieved in terms of interface design and ease of use of technologies, but today the focus has noticeably shifted toward new services, applications and devices that can be offered to prevent, compensate, care and enhance to make one's life better - independently of age. In this regards, an important point of discussion and future work is related to the challenge of achieving the right balance between both an accessible and universal IT design for active ageing. A right balance should shape technology in such a way that it will respond better to the needs of the ageing population, without stigmatizing them nor overly focusing on the limitations side. Other than compensating and supporting care, ICTs are transitioning to a more active role in preventing decline and enhancing life with new 
opportunities. Beyond any doubt, the role that IT played so far in enabling this transition was crucial, and it's potential and contributions are far from over. 



\section{Acknowledgements}

The authors would like to thank all the members of the Life Participation Group for their support. This work was partially funded by the Province of Trento (project "Anchise Portale RSA"), the EIT (project "Personal Fitness Club") and the project in "Evaluation and enhancement of social, economic and emotional wellbeing of older adults" (under the Agreement No.14.Z50.31.0029). We would also like to give special thanks to the people and organizations who took us in as part of their communities, giving us the opportunity to work closely with the people our research was about: to all the people from the Older Adults Services Center "CSA Contrada Larga", managed by the social cooperative Kaleidoscopio in Trento, Italy; to Francesca Burli and the people living in the assisted care living residence "RSA Brentonico" in Brentonico, Italy; to Maria Messmer-Capaul and her team of the "Fachstelle für präventive Beratung Spitex-Zürich" in Zürich, Switzerland; and to Claudia Nüesch of the "Senioren Begegnungszentrum Baumgärtlihof". 



\section{Appendices}





\section{A}

\section{Active Ageing Determinants}

Tables in this section provide an additional description of each Active Ageing determinant. As we introduced in Section 2.2, determinants are influences that surround individuals and which the process of Active Ageing depends on. They are divided into six categories according to the WHO [182]. Tables I-VI describe each category by means of their specific determinants. 
Table A.1: Active Ageing Health Services determinants

\begin{tabular}{|l|l|}
\hline Determinant & Description \\
\hline Cure services & $\begin{array}{l}\text { Health services that provide attention and } \\
\text { recovery treatment when an emergency is } \\
\text { triggered (either because of a disease or } \\
\text { an accident) or when the person endures } \\
\text { a chronic health condition or disease that } \\
\text { demands constant treatment. For example, } \\
\text { a cure service can help to avoid long term } \\
\text { loss of capabilities, helping people to stay } \\
\text { active faster and for longer. }\end{array}$ \\
\hline Care services & $\begin{array}{l}\text { Availability and quality of healthcare and } \\
\text { long-term care for older adults in the place } \\
\text { they live. For example, constant and } \\
\text { good care can ease the burden of age re- } \\
\text { lated limitations, helping people to feel } \\
\text { good and facilitating their participation in } \\
\text { social or personal activities. }\end{array}$ \\
\hline Prevention services & $\begin{array}{l}\text { Health services to prevent potential physi- } \\
\text { cal or cognitive losses. For example, vacci- } \\
\text { nating older adults against influenza pre- } \\
\text { vents them from being affected by this dis- } \\
\text { ease and related complications, potentially } \\
\text { alleviating also the economic cost of treat- } \\
\text { ments. }\end{array}$ \\
\hline
\end{tabular}

Description of active ageing determinants related to the Health Services category 
Table A.2: Active Ageing Behavioral determinants

\begin{tabular}{|l|l|}
\hline Determinant & Description \\
\hline ment & $\begin{array}{l}\text { Level of compliance of a person in following } \\
\text { medication and treatment. For example, if } \\
\text { a person adheres correctly to a prescribed } \\
\text { treatment, his or her health conditions will } \\
\text { improve faster or the burden of diseases } \\
\text { gets reduced. }\end{array}$ \\
\hline Lifestyle & $\begin{array}{l}\text { The individuals' way of living manifested } \\
\text { in activities, attitudes and interests. For } \\
\text { example, participation in regular, moder- } \\
\text { ate physical activity can delay functional } \\
\text { decline. }\end{array}$ \\
\hline
\end{tabular}

Description of active ageing determinants related to the Economical category

Table A.3: Active Ageing Personal determinants

\begin{tabular}{|l|l|}
\hline Determinant & Description \\
\hline Psychological factors & $\begin{array}{l}\text { Everything that makes to a person's psy- } \\
\text { chology like its cognitive capacity, motiva- } \\
\text { tion, self-efficacy and self-esteem. For ex- } \\
\text { ample, a good self-esteem will make it eas- } \\
\text { ier for people to adopt healthy lifestyles. }\end{array}$ \\
\hline $\begin{array}{l}\text { Biological and Ge- } \\
\text { netic factors }\end{array}$ & $\begin{array}{l}\text { A person's intrinsic biological characteris- } \\
\text { tics and inherited health conditions and } \\
\text { limitations, including also its inherited or } \\
\text { acquired physical limitations. For example, } \\
\text { physical conditions like constant tremors } \\
\text { of the hands can reduce the type of activ- } \\
\text { ities a person can engage in. }\end{array}$ \\
\hline
\end{tabular}

Description of active ageing determinants related to the Personal category 
Table A.4: Active Ageing Environmental determinants

\begin{tabular}{|l|l|}
\hline Determinant & Description \\
\hline portation and Trans- & $\begin{array}{l}\text { Opportunities for, and quality of, mobility } \\
\text { and transportation systems existing in the } \\
\text { environment. For example, a good public } \\
\text { transportation system can facilitate people } \\
\text { to stay in touch visiting friends and family. }\end{array}$ \\
\hline $\begin{array}{l}\text { Age-friendly infras- } \\
\text { tructure }\end{array}$ & $\begin{array}{l}\text { Availability of infrastructure that it is ac- } \\
\text { commodating to disabilities that may ap- } \\
\text { pear as we grow old. For example, ramps } \\
\text { for accessing building. }\end{array}$ \\
\hline $\begin{array}{l}\text { Communication ac- } \\
\text { cess }\end{array}$ & $\begin{array}{l}\text { Infrastructure for communication and } \\
\text { availability of communication means. This } \\
\text { determinant has a role in supporting el- } \\
\text { ders' social relationships, for example, } \\
\text { keeping them in touch with relatives and } \\
\text { friends living abroad. }\end{array}$ \\
\hline $\begin{array}{l}\text { Housing and daily } \\
\text { living }\end{array}$ & $\begin{array}{l}\text { How supportive is a person's housing envi- } \\
\text { ronment to facilitate performance of daily } \\
\text { chores and activities. For example, the } \\
\text { availability of ramps or wheelchair stairs } \\
\text { lifts can be key in facilitating the life of } \\
\text { people with physical impairments, allow- } \\
\text { ing them to maintain independence. }\end{array}$ \\
\hline and food water, air & $\begin{array}{l}\text { The quality and availability of air, food } \\
\text { and water in the environment. For exam- } \\
\text { ple, clean water is fundamental for those } \\
\text { who have a fragile health (i.e. people with } \\
\text { chronic illnesses and compromised immune } \\
\text { systems) can reduce the type of activities } \\
\text { a person can engage in. }\end{array}$ \\
\hline
\end{tabular}

Description of active ageing determinants related to the Environmental category 
Table A.5: Active Ageing Social determinants

\begin{tabular}{|l|l|}
\hline Determinant & Description \\
\hline Risk of violence and & $\begin{array}{l}\text { Level of insecurity in the social environ- } \\
\text { ment. For example, older adults who are } \\
\text { frail live alone may feel particularly vul- } \\
\text { nerable to crimes and such as theft, and } \\
\text { hence limit their participation in social ac- } \\
\text { tivities. }\end{array}$ \\
\hline Education & $\begin{array}{l}\text { Quality and availability of education op- } \\
\text { portunities in the social environment. For } \\
\text { example, low levels of education can result } \\
\text { in difficulties for finding jobs as we become } \\
\text { older workers. }\end{array}$ \\
\hline Social support & $\begin{array}{l}\text { Quality and availability of support and so- } \\
\text { cial interactions in a person's social net- } \\
\text { work. For example, supportive social con- } \\
\text { nections and intimate relations are vital } \\
\text { sources of emotional strength. }\end{array}$ \\
\hline
\end{tabular}

Description of active ageing determinants related to the Social category 
Table A.6: Active Ageing Economical determinants

\begin{tabular}{|l|l|}
\hline Determinant & Description \\
\hline Income & $\begin{array}{l}\text { Level of income perceived by individuals. } \\
\text { For example, better income can guarantee } \\
\text { access to better, healthier diet. }\end{array}$ \\
\hline Employment & $\begin{array}{l}\text { Opportunities and quality for employ- } \\
\text { ment, volunteering or leisure time activ- } \\
\text { ities. For example, access to employment } \\
\text { through volunteering in old age can help } \\
\text { people to feel useful for contributing mean- } \\
\text { ingful in society. }\end{array}$ \\
\hline
\end{tabular}

Description of active ageing determinants related to the Economical category 


\section{References}

[1] I.M. Albaina, T. Visser, C.A.P.G. van der Mast, and M.H. Vastenburg. Flowie: A persuasive virtual coach to motivate elderly individuals to walk. In PervasiveHealth'09. IEEE, 2009.

[2] N.M. Ali, S. Shahar, Y.L. Kee, A.R. Norizan, and S.A.M. Noah. Design of an interactive digital nutritional education package for elderly people. Informatics for Health and Social Care, 2012.

[3] Majd Alwan, PJ Rajendran, S Kell, D. Mack, S. Dalal, M. Wolfe, and R. Felder. A Smart and Passive Floor-Vibration Based Fall Detector for Elderly. In ICTTA'06. IEEE, 2006. ISBN 0-7803-9521-2.

. URL http://ieeexplore .ieee.org/xpls/abs_all.jsp?arnumber= 1684511http://ieeexplore.ieee.org/lpdocs/epic03/wrapper. htm?arnumber $=1684511$

[4] Majd Alwan, Devon Wiley, and Jeremy Nobel. State of technology in aging services. Technical report, Center for Aging Services Technologies (CAST), 2007.

[5] Michelle Annett, Fraser Anderson, Darrell Goertzen, Jonathan Halton, Quentin Ranson, Walter F. Bischof, and Pierre Boulanger. Using a multi-touch tabletop for upper extremity motor rehabilitation. In OZCHI '09, 2009. ISBN 9781605588544. . URL http://portal.acm. org/citation.cfm?doid=1738826.1738869. 
[6] Kofi Appiah, Andrew Hunter, and Christopher Waltham. Lowpower and efficient ambient assistive care system for elders. In CVPRW'11 Workshop. IEEE, 2011. ISBN 978-1-4577-0529-8. . URL http://ieeexplore.ieee.org/lpdocs/epic03/wrapper.htm? arnumber $=5981824$.

[7] Trent Apted, Judy Kay, and Aaron Quigley. Tabletop sharing of digital photographs for the elderly. In CHI'06. ACM Press, 2006. ISBN 1595933727. . URL http://dl.acm.org/citation.cfm?id= 1124887http://portal.acm.org/citation. cfm?doid=1124772. 1124887 .

[8] Karlene Ball, Jerri D Edwards, Lesley A Ross, and Gerald McGwin Jr. Cognitive training decreases motor vehicle collision involvement of older drivers. Journal of the American Geriatrics Society, 58(11):2107-2113, 2010.

[9] Paul B Baltes and Margret M Baltes. Successful aging: Perspectives from the behavioral sciences, volume 4. Cambridge University Press, 1993.

[10] Richard Banks and Abigail Sellen. Shoebox: mixing storage and display of digital images in the home. In TEI'09. ACM, 2009. ISBN 978-160558-493-5. . URL/http://doi.acm.org/10.1145/1517664.1517678.

[11] Chandramallika Basak, Walter R Boot, Michelle W Voss, and Arthur F Kramer. Can training in a real-time strategy video game attenuate cognitive decline in older adults? Psychology and aging, 23(4):765, 2008.

[12] Scott Beach, Richard Schulz, Julie Downs, Judith Matthews, Bruce Barron, and Katherine Seelman. Disability, age, and informational privacy attitudes in quality of life technology applications: Results from a national web survey. ACM Transactions on Accessible Computing (TACCESS), 2(1):5, 2009.

[13] Shirley Ann Becker. A study of web usability for older adults seeking online health resources. ACM Transactions on Computer-Human Interaction (TOCHI), 11(4):387-406, 2004.

[14] M-M. Bernard, M. Fruhwirth, M. Brooks, K. Oakley, X. Wang, K.G. Ouechni, and F. Janson. Intergenerational telementoring for the promotion of social relationships. Gerontechnology, 2011. ISSN 1569-111X. . URL http://www.gerontechnology.info/index.php/ journal/article/view/gt.2011.10.01.005.00.

[15] Margit Biemans and Betsy Van Dijk. Food for talk: photo frames to support social connectedness for elderly people in a nursing home. In $E C C E$ '09, 2009. URL http://dl .acm.org/citation.cfm?id=1690528. 
[16] Jeffrey P Bigham, Craig M Prince, and Richard E Ladner. Webanywhere: a screen reader on-the-go. In Proceedings of the 2008 international cross-disciplinary conference on Web accessibility (W4A), 2008.

[17] Matthew N Bonner, Jeremy T Brudvik, Gregory D Abowd, and W Keith Edwards. No-look notes: Accessible eyes-free multi-touch text entry. In Pervasive Computing. Springer, 2010.

[18] Walter R Boot and Daniel J Simons. Advances in video game methods and reporting practices (but still room for improvement): a commentary on strobach, frensch, and schubert (2012). Acta psychologica, 141(2): 276-277, 2012.

[19] Walter R Boot, Daniel P Blakely, and Daniel J Simons. Do action video games improve perception and cognition? Frontiers in Psychology, 2, 2011.

[20] H Bouma, RA Weale, and C McCreadie. Technological environments for visual independence in later years. Gerontechnology, 2006.

[21] Alan K Bourke, Pepijn W J van de Ven, Amy E Chaya, Gearóid M OLaighin, and John Nelson. Testing of a long-term fall detection system incorporated into a custom vest for the elderly. In $I E M B S$ ' 08 , January 2008. ISBN 9781424418152. . URL http://www.ncbi.nlm.nih.gov/ pubmed/19163298.

[22] Cynthia Breazeal. Social robots for health applications. In IEMBS'11, 2011. ISBN 9781424441228. . URL http://www.ncbi.nlm.nih.gov/ pubmed/22255551.

[23] Dan Buettner. The Blue Zones: 9 Lessons for Living Longer from the People Who've Lived the Longest. National Geographic Books, 2012.

[24] C Buiza, J Soldatos, T Petsatodis, and A Geven. HERMES: Pervasive computing and cognitive training for ageing well. Distributed Computing,, 2009. URL http://www.springerlink.com/ index/0535Q2127J316434.pdf

[25] S. Byun and C. Park. Serious game for cognitive testing of elderly. In HCI International. Posters' Extended Abstracts. Springer, 2011.

[26] María F. Cabrera-Umpiẃrrez, Viveca Jiménez, María M. Fernández, Jesús Salazar, and Miguel A. Huerta. eHealth services for the elderly at home and on the move. In IST-Africa '10, 2010. ISBN 9781905824199. URL http://ieeexplore.ieee.org/xpls/abs_all. jsp?arnumber $=5753019$ 
[27] K.E. Caine, C.Y. Zimmerman, Z. Schall-Zimmerman, W.R. Hazlewood, L. Jean Camp, K.H. Connelly, L.L. Huber, and K. Shankar. Digiswitch: A device to allow older adults to monitor and direct the collection and transmission of health information collected at home. Journal of medical systems, 2011.

[28] Yabo Cao, Yujiu Yang, and WenHuang Liu. E-FallD: A fall detection system using android-based smartphone. In FSKD'12, 2012. ISBN 9781-4673-0024-7. . URL http://ieeexplore.ieee.org/lpdocs/epic03/ wrapper.htm?arnumber $=6234271$.

[29] Stefan Carmien, Melissa Dawe, Gerhard Fischer, Andrew Gorman, Anja Kintsch, and James F. Sullivan. Socio-technical environments supporting people with cognitive disabilities using public transportation. ACM Transactions on CHI, 2005. ISSN 10730516. . URL http://portal.acm.org/citation. cfm?doid=1067860.1067865.

[30] Stefan Parry Carmien and Gerhard Fischer. Design, adoption, and assessment of a socio-technical environment supporting independence for persons with cognitive disabilities. In CHI'08, 2008. ISBN 9781605580111. . URL http://dl.acm.org/citation.cfm?id=1357151http://portal. acm. org/citation. .fm?doid=1357054.1357151.

[31] Neil Charness, George Demiris, and Elizabeth Krupinski. Designing telehealth for an aging population: A human factors perspective. CRC Press, 2011.

[32] Yung-Chin Chen and Yi-Wen Lin. Indoor RFID gait monitoring system for fall detection. In ISAC'10, November 2010. ISBN 978-1-4244-8313-6. . URL http://ieeexplore . ieee.org/lpdocs/epic03/wrapper.htm? arnumber $=5670478$.

[33] I.T. Chiang, J.C. Tsai, and S.T. Chen. Using xbox 360 kinect games on enhancing visual performance skills on institutionalized older adults with wheelchairs. In IEEE DIGITEL'12. IEEE, 2012.

[34] Brenna Cholerton, Laura D Baker, and Suzanne Craft. Insulin, cognition, and dementia. European journal of pharmacology, 719(1):170-179, 2013.

[35] European Commission. Taking forward the Strategic Implementation Plan of the European Innovation Partnership on Active and Healthy Ageing. Technical report, European Commission, 2012.

[36] L.G. Concannon, M.J. Grierson, and M.A. Harrast. Exercise in the older adult: from the sedentary elderly to the masters athlete. $P M R$, 2012. 
[37] S. Consolvo, P. Klasnja, D.W. McDonald, and J.A. Landay. Goal-setting considerations for persuasive technologies that encourage physical activity. In PERSUASIVE '09. ACM, 2009.

[38] Sunny Consolvo, Peter Roessler, B.E. Shelton, A. LaMarca, B. Schilit, and S. Bly. Technology for care networks of elders. IEEE Pervasive Computing, 2004. ISSN 1536-1268. . URL http://ieeexplore.ieee. org/xpls/abs_all.jsp?arnumber=1316814http://ieeexplore. ieee.org/lpdocs/epic03/wrapper.htm?arnumber $=1316814$

[39] R Cornejo-García. Strengthening Elder's Social Networks through Ambient Information Systems and SNS. In CSCW'10, 2010. ISBN 9781605587950. URL http://usuario.cicese.mx/ rcornejo/pub_ files/cscw2010_DC.pdfhttp://research.microsoft.com/en-us/ um/redmond/groups/connect/cscw_10/docs/p519.pdf.

[40] Sara J Czaja and Joseph Sharit. Designing training and instructional programs for older adults. CRC Press, 2012.

[41] Eling D de Bruin. Towards standardised evaluation tools. Age and ageing, 2012.

[42] Wagner O. de Morais and Nicholas Wickstrom. A serious computer game to assist Tai Chi training for the elderly. In IEEE SeGAH'11. IEEE, 2011. ISBN 978-1-4673-0434-4. . URL http://ieeexplore. ieee.org/lpdocs/epic03/wrapper.htm?arnumber $=6165450$

[43] Rodrigo De Oliveira, Mauro Cherubini, and Nuria Oliver. Movipill: improving medication compliance for elders using a mobile persuasive social game. In Ubicomp '10. ACM, 2010. ISBN 978-1-60558-843-8. . URL http://doi.acm.org/10.1145/1864349.1864371.

[44] Ian J Deary, Janie Corley, Alan J Gow, Sarah E Harris, Lorna M Houlihan, Riccardo E Marioni, Lars Penke, Snorri B Rafnsson, and John M Starr. Age-associated cognitive decline. British medical bulletin, 92(1): 135-152, 2009.

[45] J. Derboven, M. Van Gils, and D. De Grooff. Designing for collaboration: a study in intergenerational social game design. Universal Access in the Information Society, 2012.

[46] Marco Dianti, Cristhian Parra, Fabio Casati, and Antonella De Angelli. What's Up: Fostering Intergenerational Social Interactions. In Designing for Inter/Generational Communities. IRSI, 2012.

[47] JW Dodd, SV Getov, and PW Jones. Cognitive function in copd. European Respiratory Journal, 35(4):913-922, 2010. 
[48] Charalampos Doukas and Ilias Maglogiannis. Advanced patient or elder fall detection based on movement and sound data. In ICPCTH'08, January 2008. ISBN 978-963-9799-15-8. . URL http://ieeexplore. ieee.org/lpdocs/epic03/wrapper.htm?arnumber $=4571042$

[49] Charalampos N Doukas and Ilias Maglogiannis. Emergency fall incidents detection in assisted living environments utilizing motion, sound, and visual perceptual components. IEEE Transactions on IT in Biomed., 2011. ISSN 1558-0032. . URL http://www.ncbi.nlm.nih. gov/pubmed/21062686

[50] Elena Portacolone. Precariousness among older adults living alone in San Francisco: An ethnography. PhD thesis, UNIVERSITY OF CALIFORNIA, SAN FRANCISCO, 2011.

[51] Shih-Hau Fang, Yi-Chung Liang, and Kuan-Ming Chiu. Developing a mobile phone-based fall detection system on Android platform. In ComComAp'12. IEEE, 2012. ISBN 978-1-4577-1719-2. . URL http://ieeexplore.ieee.org/lpdocs/epic03/wrapper.htm? arnumber $=6154019$.

[52] I.K. Far, P. Silveira, F. Casati, and M. Baez. Unifying platform for the physical, mental and social well-being of the elderly. Embedded and Multimedia Computing Technology and Service, 2012.

[53] J. Fasola and MJ Mataric. Robot exercise instructor: A socially assistive robot system to monitor and encourage physical exercise for the elderly. In IEEE RO-MAN '10. Citeseer, 2010.

[54] Antonio Fernández-Caballero, Marina V. Sokolova, Juan SerranoCuerda, Jose Carlos Castillo, Veronica Moreno, Rodrigo Castineira, and Luis Redondo. HOLDS: Efficient Fall Detection through Accelerometers and Computer Vision. In IE'12. IEEE, 2012. ISBN 978-1-4673-2093-1. . URL http://ieeexplore.ieee.org/lpdocs/epic03/wrapper.htm? arnumber $=6258554$.

[55] L. Ferrucci, J.M. Guralnik, S. Studenski, L.P. Fried, G.B. Cutler Jr, and J.D. Walston. Designing randomized, controlled trials aimed at preventing or delaying functional decline and disability in frail, older persons: a consensus report. J Am Geriatr Soc, 2004.

[56] Arthur D Fisk, Wendy A Rogers, Neil Charness, Sara J Czaja, and Joseph Sharit. Designing for older adults: Principles and creative human factors approaches. CRC press, 2012.

[57] Brian J Fogg. Persuasive technology: using computers to change what we think and do. Ubiquity, 2002. 
[58] Laura Fratiglioni, Stephanie Paillard-Borg, and Bengt Winblad. An active and socially integrated lifestyle in late life might protect against dementia. The Lancet Neurology, 3(6):343-353, 2004.

[59] Juan Pablo García-Vázquez, Marcela D. Rodríguez, Ángel G. Andrade, and José Bravo. Supporting the strategies to improve elders' medication compliance by providing ambient aids. Pers. and Ubiq. Computing, 2011. ISSN 1617-4909. . URL http://www.springerlink.com/index/ $10.1007 / \mathrm{s} 00779-010-0362-0$.

[60] K.M. Gerling, J. Schild, and M. Masuch. Exergame design for elderly users: the case study of silverbalance. In ACE'10. ACM, 2010.

[61] K.M. Gerling, F.P. Schulte, and M. Masuch. Designing and evaluating digital games for frail elderly persons. In $A C E$ '11, 2011.

[62] Orestis Giotakos, Katerina Tsirgogianni, and Ioannis Tarnanas. A virtual reality exposure therapy (VRET) scenario for the reduction of fear of falling and balance rehabilitation training of elder adults with hip fracture history. In VR'07, September 2007. ISBN 978-1-4244-1203-7. . URL http://ieeexplore .ieee.org/lpdocs/epic03/wrapper.htm? arnumber $=4362157$.

[63] T.C. Goldsmith. On the programmed/non-programmed aging controversy. Biochemistry, 2012. ISSN 0006-2979. . URL http://dx.doi. org/10.1134/S000629791207005X.

[64] Andrew Gorman, Anja Kintsch, and Stefan Carmien. Lifeline. Technical report, CLLD. University of Colorado Boulder, 2003. URL www.cs. colorado.edu/ 13d/clever.

[65] Gary Gowans, Jim Campbell, Norm Alm, Richard Dye, Arlene Astell, and Maggie Ellis. Designing a multimedia conversation aid for reminiscence therapy in dementia care environments. In CHI EA'04, 2004. ISBN 1581137036. . URL http://portal.acm.org/citation.cfm? doid=985921.985943http://dl. acm.org/citation . cfm?id=985943.

[66] Guendalina Graffigna, Serena Barello, Brenda K Wiederhold, A Claudio Bosio, and Giuseppe Riva. Positive technology as a driver for health engagement. Annual Review of Cybertherapy and Telemedicine 2013, page 9, 2013.

[67] A. Grimes, V. Kantroo, and R.E. Grinter. Let's play!: mobile health games for adults. In Ubicomp'10, 2010. 
[68] J.M. Guralnik, E.M. Simonsick, L. Ferrucci, R.J. Glynn, L.F. Berkman, D.G. Blazer, P.A. Scherr, and R.B. Wallace. A short physical performance battery assessing lower extremity function: association with self-reported disability and prediction of mortality and nursing home admission. J Gerontol, 1994.

[69] J.M. Guralnik, L. Ferrucci, E.M. Simonsick, M.E. Salive, and R.B. Wallace. Lower-extremity function in persons over the age of 70 years as a predictor of subsequent disability. N Engl J Med, 1995.

[70] J.M. Guralnik, L.P. Fried, and M.E. Salive. Disability as a public health outcome in the aging population. Annu Rev Public Health, 1996.

[71] Laura K Hamilton, Sandra E Joppé, LoÑŮc M Cochard, and Karl JL Fernandes. Aging and neurogenesis in the adult forebrain: what we have learned and where we should go from here. European journal of neuroscience, 37(12):1978-1986, 2013.

[72] S.T. Hansen. Robot games for elderly. In HRI'11. ACM, 2011.

[73] S.E. Hardy, Y. Kang, S.A. Studenski, and H.B. Degenholtz. Ability to walk Âij mile predicts subsequent disability, mortality, and health care costs. J Gen Intern Med, 2011.

[74] Thomas L Harrington and Marcia K Harrington. GERONTECHNOLOGY Why and How. Shaker, 2000.

[75] John F HELLIWELL and Robert D PUTNAM. The social context of well-being. Philosophical transactions-Royal Society of London. Biological sciences, 359(1449):1435-1446, 2004.

[76] Loc Ho, Melody Moh, Zachary Walker, Takeo Hamada, and ChingFong Su. A prototype on rfid and sensor networks for elder healthcare: progress report. In EWIND'05. ACM, 2005. ISBN 1-59593-026-4. . URL http://doi .acm .org/10.1145/1080148.1080164.

[77] Andreas Holzinger, Gig Searle, Stephan Pruckner, Silke SteinbachNordmann, Thomas Kleinberger, Etienne Hirt, and Jens Temnitzer. Perceived usefulness among elderly people: Experiences and lessons learned during the evaluation of a wrist device. In PervasiveHealth'10. IEEE, 2010. ISBN 978-963-9799-89-9. . URL http:// ieeexplore . ieee .org/xpls/abs_all . jsp?arnumber=5482228http: //eudl.eu/doi/10.4108/ICST.PERVASIVEHEALTH2010.8912 
[78] Sandra Huertas, Juan P Lazaro, Sergio Guillen, and Vicente Traver. Information and assistance bubbles to help elderly people in public environments. In IEMBS'10, 2010. ISBN 9781424441242. . URL http://ieeexplore .ieee.org/xpls/abs_all.jsp?arnumber= 5627875http://www.ncbi.nlm.nih.gov/pubmed/21097182

[79] Rosa Iglesias, Nuria Gomez de Segura, and Miren Iturburu. The elderly interacting with a digital agenda through an RFID pen and a touch screen. In MSIADU '09, 2009. ISBN 9781605587646. . URL http: //portal.acm.org/citation.cfm?doid=1631097.1631108

[80] Susanne Iwarsson and Agnetha Ståhl. Accessibility, usability and universal design-positioning and definition of concepts describing personenvironment relationships. Disability \& Rehabilitation, 25(2):57-66, 2003.

[81] H. Jimison, M. Pavel, J. McKanna, and J. Pavel. Unobtrusive monitoring of computer interactions to detect cognitive status in elders. IEEE Trans. on Information Technology in Biomedicine, 2004.

[82] H. Jimison, J. McKanna, K. Ambert, S. Hagler, W. Hatt, and M. Pavel. Models of cognitive performance based on home monitoring data. In EMBS'10, 2010.

[83] Y. Jung, K.J. Li, N.S. Janissa, W.L.C. Gladys, and K.M. Lee. Games for a better life: effects of playing wii games on the well-being of seniors in a long-term care facility. In ACM IE'09. ACM, 2009.

[84] M. Kaenampornpan, T. Anuchad, and P. Supaluck. Fall detection prototype for Thai elderly in mobile computing era. In ECTICON'11. IEEE, 2011. ISBN 978-1-4577-0425-3. . URL http://ieeexplore.ieee.org/ lpdocs/epic03/wrapper.htm?arnumber $=5947871$.

[85] Mirja Kälviäinen. Elderly as content providers in their everyday life supporting services. Technical report, Karelia University of Applied Sciences, 2012.

[86] Maria Karavidas, Nicholas K. Lim, and Steve L. Katsikas. The effects of computers on older adult users. Computers in Human Behavior, 2005. ISSN 07475632. . URL http://linkinghub.elsevier.com/retrieve/ pii/S0747563204000597.

[87] S. Katz, L.G. Branch, M.H. Branson, J.A. Papsidero, J.C. Beck, and D.S. Greer. Active life expectancy. N Engl J Med, 1983.

[88] P. Keyani, G. Hsieh, B. Mutlu, M. Easterday, and J. Forlizzi. Dancealong: supporting positive social exchange and exercise for the elderly through dance. In CHI EA'05. ACM, 2005. 
[89] Manton K.G. The global impact of noncommunicable diseases: estimates and projections. World health statistics quarterly. Rapport trimestriel de statistiques sanitaires mondiales, 1988.

[90] Eng Tat Khoo, Adrian David Cheok, Ta Huynh Duy Nguyen, and Zhigeng Pan. Age invaders: social and physical inter-generational mixed reality family entertainment. Virtual Reality, 2008. ISSN 1359-4338. . URL http://www.springerlink.com/index/10.1007/ s10055-008-0083-0.

[91] Julie A Kientz, Shwetak N Patel, Brian Jones, ED Price, Elizabeth D Mynatt, and Gregory D Abowd. The georgia tech aware home. In $C H I$ EA'08, 2008.

[92] K.S. Kim, S.S. Oh, J.H. Ahn, and S.H. Lee. Development of a walking game for the elderly using controllers of hand buttons and foot boards. In CGAMES'12. IEEE, 2012.

[93] Norbert Kiss, Gergely Patai, and P Hanak. Vital fitness and health telemonitoring of elderly people. In MIPRO'11, 2011. URL http: //ieeexplore.ieee.org/xpls/abs_all.jsp?arnumber=5967065.

[94] J.L. Koay, J.S. Ng, and G.L.C. Wong. Nintendo wii as an intervention: improving the well-being of elderly in long-term care facilities. Technical report, Nanyang Technological University, 2010.

[95] Masatomo Kobayashi, Atsushi Hiyama, Takahiro Miura, Chieko Asakawa, Michitaka Hirose, and Tohru Ifukube. Elderly user evaluation of mobile touchscreen interactions. In INTERACT 2011, 2011. ISBN 978-3-642-23773-7. . URL http://dx.doi.org/10.1007/ 978-3-642-23774-4_9.

[96] E. Lawrence, C. Sax, K.F. Navarro, and M. Qiao. Interactive games to improve quality of life for the elderly: Towards integration into a wsn monitoring system. In ETELEMED'10. IEEE, 2010.

[97] J.P. Lázaro, A. Fides, A. Navarro, and S. Guillén. Ambient assisted nutritional advisor for elderly people living at home. In IEEE EMBC'10. IEEE, 2010.

[98] Junghyun H Lee, Yera Choi, Chansoo Jun, Young Sun Hong, Han Byul Cho, Jieun E Kim, and In Kyoon Lyoo. Neurocognitive changes and their neural correlates in patients with type 2 diabetes mellitus. Endocrinology and Metabolism, 29(2):112-121, 2014. 
[99] C Leonardi, C Mennecozzi, and E Not. Supporting older adults social network: the design of e-inclusion communication services. Gerontechnology, 2008. URL http://gerontechnology.info/index.php/ journal/article/download/gt.2008.07.02.090.00/821.

[100] K.Z.H. Li and U. Lindenberger. Relations between aging sensory/sensorimotor and cognitive functions. Neurosci Biobehav Rev, 2002.

[101] S.E. Siân E Lindley, R. Harper, Abigail Sellen, and Cambridge Cb. Desiring to be in touch in a changing communications landscape: attitudes of older adults. In CHI'09, 2009. ISBN 9781605582467. URL http://dl.acm.org/citation.cfm?id=1518962.

[102] Siân E Lindley. Shades of lightweight: Supporting cross-generational communication through home messaging. Universal Access in the Information Society, 2012.

[103] Chi Harold Liu, Jiajia Wen, Qi Yu, Bo Yang, and Wenjie Wang. HealthKiosk: A family-based connected healthcare system for longterm monitoring. In IEEE INFOCOMW'11. IEEE, 2011. ISBN 978-14577-0249-5. . URL http://ieeexplore.ieee.org/lpdocs/epic03/ wrapper.htm?arnumber $=5928816$.

[104] Yikun Liu and Haidan Huang. Timecapsule: connecting past. In CHI EA'11. ACM, 2011. ISBN 978-1-4503-0268-5. . URL http://doi .acm. org/10.1145/1979742.1979505

[105] Tharindu Rekha Liyanagunawardena, Andrew Alexandar Adams, and Shirley Ann Williams. Moocs: A systematic study of the published literature 2008-2012. The International Review of Research in Open and Distance Learning, 2013. ISSN 1492-3831. URL http://www.irrodl. org/index.php/irrodl/article/view/1455

[106] Bruno Loureiro and Rui Rodrigues. Multi-touch as a natural user interface for elders: A survey. In CISTI'11. IEEE, 2011.

[107] AB Lynggaard and MG Petersen. Home awareness. connecting people sensuously to places. In $D I S^{\prime} 10,2010$. ISBN 9781450301039. URL http://dl.acm.org/citation.cfm?id=1858251.

[108] Ronald L Mace, Graeme J Hardie, and Jaine P Place. Accessible environments: Toward universal design. Center for Accessible Housing, North Carolina State University, 1990. 
[109] Abdullah Al Mahmud, Omar Mubin, Suleman Shahid, and JeanBernard Martens. Designing social games for children and older adults: Two related case studies. Entertainment Computing, 2010. ISSN 18759521. . URL http://linkinghub.elsevier.com/retrieve/pii/ S1875952110000066.

[110] Fillia Makedon, Rong Zhang, Georgios Alexandrakis, C.B. Owen, Heng Huang, and A.J. Saykin. An interactive user interface system for Alzheimer's intervention. In PETRA'10. ACM, 2010. URL http: //dl.acm.org/citation. cfm?id=1839336

[111] N. Malanowski, R. Ozcivelek, and M. Cabrera. Active ageing and independent living services: The role of information and communication technology. Technical report, JRC-IPTS, 2008.

[112] Christelle Mandin. Active ageing in europe. In ESPAnet '04, number September, 2004.

[113] C. McCall, B. Maynes, C.C. Zou, and N.J. Zhang. An automatic medication self-management and monitoring system for independently living patients. Medical Engineering \& Physics, 2012.

[114] Rajesh Kannan Megalingam, Vineeth Radhakrishnan, Denny Chakko Jacob, Deepak Krishnan Melepurath Unnikrishnan, and Akhil Kakkanattu Sudhakaran. Assistive Technology for Elders: Wireless Intelligent Healthcare Gadget. In IEEE GHTC'11, October 2011. ISBN 978-1-61284-634-7. . URL http://ieeexplore.ieee. org/lpdocs/epic03/wrapper. htm?arnumber $=6103653$.

[115] Anne-Sophie Melenhorst, Arthur D Fisk, Elizabeth D Mynatt, and Wendy A Rogers. Potential intrusiveness of aware home technology: Perceptions of older adults. In HFES Annual Meeting'04, 2004.

[116] Victoria Meza-Kubo, Alberto L. Moran, and Marcela D. Rodriguez. Intergenerational communication systems in support for elder adults with cognitive decline. In ICST PERVASIVEHEALTH'09. ICST, 2009. . URL http://eudl. eu/doi/10.4108/ICST . PERVASIVEHEALTH2009. 6069.

[117] Michael Millar, BBC News. How old age technology could help stop a demographic time bomb. http://www.bbc.co.uk/news/ business-21535772, 2013.

[118] Roger W Morrell. Older adults, health information, and the World Wide Web. Psychology Press, 2001.

[119] J.H Morrison and M.G. Baxter. The ageing cortical synapse: hallmarks and implications for cognitive decline. Nat Rev Neurosci, 2012. . 
[120] Andreas Motel-Klingebiel, Hans-Joachim Kondratowitz, and Clemens Tesch-Römer. Social inequality in the later life: cross-national comparison of quality of life. European Journal of Ageing, 2004.

[121] O. Mubin, S. Shahid, and A. Al Mahmud. Walk 2 win: towards designing a mobile game for elderly's social engagement. In $B C S-H C I$ '08. British Computer Society, 2008.

[122] E.D. Mynatt, A.-S. Melenhorst, A.-D. Fisk, and W.A. Rogers. Aware technologies for aging in place: understanding user needs and attitudes. IEEE Pervasive Computing, 2004. ISSN 1536-1268. . URL http://ieeexplore.ieee.org/lpdocs/epic03/wrapper.htm? arnumber $=1316816$.

[123] Elizabeth D. Mynatt, Jim Rowan, Sarah Craighill, and Annie Jacobs. Digital family portraits: supporting peace of mind for extended family members. In CHI'01. ACM, 2001. ISBN 1-58113-327-8. . URL http: //doi.acm.org/10.1145/365024.365126.

[124] Arie Hans Nasution and Sabu Emmanuel. Intelligent Video Surveillance for Monitoring Elderly in Home Environments. In IEEE MMSP'07 Workshop. IEEE, 2007. ISBN 978-1-4244-1273-0.

URL http://ieeexplore.ieee.org/xpls/abs_all.jsp?arnumber= 4412853http://ieeexplore.ieee.org/lpdocs/epic03/wrapper. htm?arnumber $=4412853$

[125] BB Neves. Too old for technology? How the elderly of Lisbon use and perceive ICT. The Journal of Community Informatics, 2012.

[126] Jakob Nielsen. Accessible design for users with disabilities. Alertbox: Current Issues in Web Usability, 1996.

[127] Mark Notess and Lesa Lorenzen-Huber. Online learning for seniors. eLearn, 2007. ISSN 1535394X. . URL http://dl.acm.org/citation.cfm?id=1266893http://portal. acm.org/citation. cfm?doid=1266885.1266893.

[128] Nanna Notthoff and Laura L Carstensen. Positive messaging promotes walking in older adults. Psychology and aging, 29(2):329, 2014.

[129] William Odom, Richard Banks, David Kirk, Richard Harper, Siân Lindley, and Abigail Sellen. Technology heirlooms? In CHI'12, 2012. ISBN 9781450310154. . URL http://dl.acm.org/citation.cfm?id= 2207723http://dl.acm.org/citation. cfm?doid=2207676.2207723.

[130] Richard Pak and Anne McLaughlin. Designing displays for older adults. CRC Press, 2010. 
[131] Cristhian Parra, Vincenzo D'Andrea, and Fabio Casati. Participatory Design of a Digital Reminiscence Application. In Demo paper at CHITALY 2013, 2013.

[132] Mark Perry and Dorothy Rachovides. Entertaining situated messaging at home. CSCW, 2007.

[133] Tanid Phiriyapokanon. Is a big button interface enough for elderly users?: Towards user interface guidelines for elderly users. Master, Mälardalen University, 2011.

[134] Wolfgang FE Preiser and Elaine Ostroff. Universal design handbook. McGraw Hill Professional, 2001.

[135] Islam Qudah, Peter Leijdekkers, and Valerie Gay. Using mobile phones to improve medication compliance and awareness for cardiac patients. In PETRA'10, 2010. ISBN 9781450300711. . URL http://portal. acm.org/citation. .fm?doid=1839294.1839337.

[136] Hayes Raffle, Janet Go, Mirjana Spasojevic, Glenda Revelle, Koichi Mori, Rafael Ballagas, Kyle Buza, Hiroshi Horii, Joseph Kaye, Kristin Cook, and Natalie Freed. Hello, is grandma there? let's read! StoryVisit. In CHI'11, 2011. ISBN 9781450302289. - URL http://dl.acm.org/citation.cfm?id=1979121http://dl. acm.org/citation. cfm?doid=1978942.1979121.

[137] Valeria Righi, A Rosales, S Sayago, and J Blat. Older people's strategies for building trust in online communities through an ethnographical lens. In NordiCHI'12 UCTIS Workshop, 2012.

[138] Marcela D Rodríguez, Victor M Gonzalez, Jesus Favela, and Pedro C Santana. Home-based communication system for older adults and their remote family. Computers in Human Behavior, 2009.

[139] Jim Rowan and Elizabeth D Mynatt. Digital Family Portrait Field Trial. In CHI'05, 2005. ISBN 1581139985. . URL http://portal. acm.org/citation. cfm?doid=1054972.1055044.

[140] J.W. Rowe and R.L. Kahn. Successful aging. The gerontologist, 1997. .

[141] Timothy A Salthouse. When does age-related cognitive decline begin? Neurobiology of aging, 30(4):507-514, 2009.

[142] W.A. Satariano, J.M. Guralnik, R.J. Jackson, R.A. Marottoli, E.A. Phelan, and T.R. Prohaska. Mobility and aging: new directions for public health action. Am J Public Health, 2012. 
[143] Sergio Sayago and Josep Blat. About the relevance of accessibility barriers in the everyday interactions of older people with the web. In W4A'09. ACM, 2009. ISBN 978-1-60558-561-1. . URL http: //doi.acm.org/10.1145/1535654.1535682.

[144] K Warner Schaie and Sherry L Willis. Handbook of the Psychology of Aging. Academic Press, 2010.

[145] Susanne Scheibe and Laura L Carstensen. Emotional aging: recent findings and future trends. The Journals of Gerontology Series B: Psychological Sciences and Social Sciences, page gbp132, 2010.

[146] G Schuhfried. CogniPlus. Technical report, Schuhfried GmbH, 2007. URL http://scholar.google.com/scholar?hl=en\&btnG=Search\&q= intitle:CogniPlus\#0

[147] Richard Schulz. Quality of life technology handbook. CRC Press, 2012.

[148] Richard Schulz and Lynn M Martire. Family caregiving of persons with dementia: prevalence, health effects, and support strategies. The American journal of geriatric psychiatry, 12(3):240-249, 2004.

[149] Abigail Sellen, Rachel Eardley, Shahram Izadi, and Richard Harper. The whereabouts clock. In CHI EA'06. ACM Press, 2006. ISBN 1595932984. - URL http://dl.acm.org/citation.cfm?id=1125694http://dl. acm.org/citation. .fm?doid=1125451.1125694.

[150] Abigail Sellen, Richard Harper, Rachel Eardley, Shahram Izadi, Tim Regan, Alex S. Taylor, and Ken R. Wood. HomeNote. In CSCW'06. ACM Press, 2006. ISBN 1595932496. URL http://dl.acm.org/citation.cfm?id=1180933http:// portal.acm.org/citation. cfm?doid=1180875.1180933.

[151] Kalpana Shankar, L Jean Camp, Kay Connelly, and Lesa Huber. Aging, Privacy, and Home-Based Computing: Developing a Design Framework. IEEE Pervasive Computing, 2012. ISSN 1536-1268. . URL http://ieeexplore.ieee.org/lpdocs/epic03/wrapper.htm? arnumber $=5740829$.

[152] Sangeetha Shekar, Prashant Nair, and Abdelsalam (Sumi) Helal. iGrocer. In $S A C$ '03, 2003. ISBN 1581136242. . URL http://portal.acm. org/citation. cfm?doid=952532.952658

[153] Wann-Yun Shieh and Ju-Chin Huang. Speedup the Multi-camera VideoSurveillance System for Elder Falling Detection. In ICESS'09. IEEE, 2009. ISBN 978-0-7695-3678-1. . URL http://ieeexplore.ieee.org/ lpdocs/epic03/wrapper.htm?arnumber $=5066668$. 
[154] Juan M. Silva, Alain Mouttham, and Abdulmotaleb El Saddik. Ubimeds: a mobile application to improve accessibility and support medication adherence. In MSIADU '09, 2009. ISBN 978-1-60558-764-6. . URL http://doi.acm.org/10.1145/1631097.1631109.

[155] Patrícia Silveira, Eva van het Reve, Florian Daniel, Fabio Casati, and Eling D. de Bruin. Tablet-based strength-balance training to motivate and improve adherence to exercise in independently living older people: a phase II preclinical exploratory trial. Journal of Medical Internet Research, 2013.

[156] S Y Sim, H S Jeon, G S Chung, S K Kim, S J Kwon, W K Lee, and K S Park. Fall detection algorithm for the elderly using acceleration sensors on the shoes. In IEMBS'11, 2011. ISBN 9781424441228. . URL http://www.ncbi.nlm.nih.gov/pubmed/22255445.

[157] Stuart T. Smith, Amir Talaei-Khoei, Mililani Ray, and Pradeep Ray. Electronic Games for Aged Care and Rehabilitation. In IEEE Healthcom'09, December 2009. ISBN 978-1-4244-5013-8. . URL http://ieeexplore. ieee.org/lpdocs/epic03/wrapper.htm? arnumber $=5406197$.

[158] D. Steffen, G. Bleser, M. Weber, D. Stricker, L. Fradet, and F. Marin. A personalized exercise trainer for elderly. In PervasiveHealth'11. IEEE, 2011.

[159] C Stephanidis, D Akoumianakis, M Sfyrakis, and A Paramythis. Universal accessibility in hci: Process-oriented design guidelines and tool requirements. In Proceedings of the 4th ERCIM Workshop on User Interfaces for all, Stockholm, Sweden, pages 19-21, 1998.

[160] Andrew Steptoe, Katie O'Donnell, Michael Marmot, and Jane Wardle. Positive affect and psychosocial processes related to health. British Journal of Psychology, 99(2):211-227, 2008.

[161] Mark Stibich. Why we age. theories and effects of aging. http:// longevity.about.com/od/longevity101/a/why_we_age.htm 2009.

[162] Walter Dan Stiehl, Cheng Hau Tong, Aseem Kishore, Matt Berlin, Jesse Gray, Cynthia Breazeal, Kuk-Hyun Han, Jeff Lieberman, Levi Lalla, Allan Maymin, Jonathan Salinas, Daniel Fuentes, and Robert Toscano. The huggable. In SIGGRAPH'06, 2006. ISBN 1595933646. . URL http://dl.acm.org/citation.cfm?id=1179149http:// portal.acm.org/citation.cfm?doid=1179133.1179149.

[163] A.A. Stone, J.E. Schwartz, J.E. Broderick, and A. Deaton. A snapshot of the age distribution of psychological well-being in the united states. Proceedings of the National Academy of Sciences, 2010. 
[164] Molly Follette Story. Maximizing usability: the principles of universal design. Assistive technology, 10(1):4-12, 1998.

[165] C Stossel and L Blessing. Tap, swipe \& pinch: Designing suitable multitouch gestures for older users. In DESIGN'10, 2010.

[166] Heidi Sugarman, Aviva Weisel-Eichler, Arie Burstin, and Riki Brown. Use of the Wii Fit system for the treatment of balance problems in the elderly: A feasibility study. In ICVR'09. IEEE, June 2009. ISBN 978-14244-4188-4. . URL http://ieeexplore.ieee.org/lpdocs/epic03/ wrapper.htm?arnumber $=5174215$

[167] Alvaro D Taveira and Sang D Choi. Review study of computer input devices and older users. HCI, 2009.

[168] Clemens Tesch-Roemer. Active Ageing And Quality Of Life In Old Age. Technical report, United Nations Economic Commission for Europe, 2012.

[169] Elizabeth Thiry, Siân Lindley, Richard Banks, and Tim Regan. Authoring personal histories: Exploring the timeline as a framework for meaning making. In CHI'13, 2013. URL http://research.microsoft.com/ apps/pubs/default.aspx?id=183443

[170] Lina Tong, Wei Chen, Quanjun Song, and Yunjian Ge. A research on automatic human fall detection method based on wearable inertial force information acquisition system. In IEEE ROBIO'09. IEEE, December 2009. ISBN 978-1-4244-4774-9. . URL http://ieeexplore.ieee.org/ lpdocs/epic03/wrapper.htm?arnumber $=5420725$.

[171] MS Uddin and Liaquat Hossain. Exploring physical, mental and psychological health for elders through their personal networks. e-Health Networking, Applications and ..., pages 29-35, 2009. URL http: //ieeexplore. ieee.org/xpls/abs_all.jsp?arnumber=5406214

[172] Debra Umberson and Jennifer Karas Montez. Social relationships and health: a flashpoint for health policy. Journal of health and social behavior, 51 Suppl:S54-66, January 2010. ISSN 0022-1465. . URL http://wWw.pubmedcentral.nih.gov/articlerender.fcgi? artid=3150158\&tool=pmcentrez\&rendertype=abstract.

[173] UNECE. Regional Implementation Strategy For The Madrid International Plan Of Action On Ageing. Technical report, United Nations Economic Commissions for Europe Ministerial Conference on Ageing, 2002. 
[174] Joshi Kumar A. V., Visu A., Mohan Raj S., Madhan Prabhu T., and Kalaiselvi V. K. G. Penpal - electronic pen aiding visually impaired in reading and visualizing textual contents. In T4E '11, 2011.

[175] Frank Vetere, Hilary Davis, Martin Gibbs, and Steve Howard. The magic box and collage: Responding to the challenge of distributed intergenerational play. Intl. Journal of HCI, 2009.

[176] K.. Wada and T.. Shibata. Living With Seal Robots-Its Sociopsychological and Physiological Influences on the Elderly at a Care House. IEEE Transactions on Robotics, 2007. ISSN 1552-3098. . URL http://ieeexplore .ieee.org/lpdocs/epic03/wrapper.htm? arnumber $=4339551$.

[177] Alan Walker and Ariela Lowenstein. European perspectives on quality of life in old age. European Journal of Ageing, 2009.

[178] Mei-Ying Wang, P.H. Tsai, J.W.S. Liu, and John K. Zao. Wedjat: A Mobile Phone Based Medicine In-take Reminder and Monitor. In IEEE BIBE'09. IEEE, 2009. ISBN 978-0-7695-3656-9. . URL http://ieeexplore .ieee.org/lpdocs/epic03/wrapper.htm? arnumber $=5211229$.

[179] G. Clare Wenger, Richard Davies, Said Shahtahmasebi, and Anne Scott. Social isolation and loneliness in old age: review and model refinement. Ageing and Society, 1996. URL http://journals.cambridge.org/ production/action/cjoGetFulltext?fulltextid=2021648

[180] David West, Aaron Quigley, and Judy Kay. MEMENTO: a digitalphysical scrapbook for memory sharing. Personal and Ubiquitous Computing, 2006. ISSN 1617-4909. . URL http://www.springerlink. com/ index/10.1007/s00779-006-0090-7.

[181] Laura A Whitlock, Anne Collins McLaughlin, and Jason C Allaire. Individual differences in response to cognitive training: Using a multi-modal, attentionally demanding game-based intervention for older adults. Computers in Human Behavior, 28(4):1091-1096, 2012.

[182] WHO. Active Ageing: A Policy Framework. Technical report, World Health Organization, 2002.

[183] WHO et al. Preamble to the constitution of the world health organization as adopted by the international health conference. Technical report, World Health Organization, June 19-22 1948. 
[184] Brenda K Wiederhold, Giuseppe Riva, and Guendalina Graffigna. Ensuring the best care for our increasing aging population: health engagement and positive technology can help patients achieve a more active role in future healthcare. Cyberpsychology, Behavior, and Social Networking, 16(6):411-412, 2013.

[185] Brenda K WIEDERHOLDa-b and RIVA Giuseppe. The quest for active and healthy ageing: What cyberpsychology can offer. Annual Review of Cybertherapy and Telemedicine 2013: Positive Technology and Health Engagement for Healthy Living and Active Ageing, 191:3, 2013.

[186] Jennifer Wiley, Ja-young Sung, and Gregory Abowd. The message center. In CHI EA'06, 2006. ISBN 1595932984. . URL http: //dl.acm.org/citation. cfm?doid=1125451.1125730.

[187] Bo Xie. Older adults, computers, and the internet: Future directions. Gerontechnology, 2003.

[188] Y Yen, C Lu, Y Cheng, J Chen, and L Fu. Towards an evidence-based and context-aware elderly caring system using persuasive engagement. Universal Access in HCI. Context Diversity, 2011. . URL http://www. springerlink.com/index/M88311061854J11M.pdf.

[189] Miao Yu, Syed Mohsen Naqvi, and Jonathon Chambers. A robust fall detection system for the elderly in a Smart Room. In IEEE ICASSP'10. IEEE, 2010. ISBN 978-1-4244-4295-9. . URL http://ieeexplore.ieee.org/xpls/abs_all.jsp?arnumber= 5495512http://ieeexplore.ieee.org/lpdocs/epic03/wrapper. htm?arnumber $=5495512$

[190] B.G. Zapirain, A.M. Zorrilla, and S. Larrañaga. Psycho-stimulation for elderly people using puzzle game. In ICE-GIC'10. IEEE, 2010.

[191] EM Zelinski and R Reyes. Cognitive benefits of computer games for older adults. Gerontechnology, 8(4):220-235, 2009.

[192] Kathryn Zickuhr and Mary Madden. Older adults and internet use. Technical report, Pew Internet \& American Life Project, 2012. URL http://pewinternet.org/Reports/2012/ Older-adults-and-internet-use.aspx. 